\title{
Time-dependent failure criteria for lifetime prediction of polymer- matrix composite structures
}

\author{
R.M. Guedes \\ Departamento de Engenharia Mecânica e Gestão Industrial, Faculdade de Engenharia da \\ Universidade do Porto, Rua Dr. Roberto Frias s/n, 4200-465 Porto, Portugal
}

\begin{abstract}
The use of fibre -reinforced polymers in civil construction applications originated structures with a high specific stiffness and strength. Although these structures usually present a high mechanical performance, their strength and stiffness may decay significantly over time. This is mainly due to the viscoelastic nature of the matrix, damage accumulation and propagation within the matrix and fibre breaking. One serious consequence, as a result of static fatigue (creep failure), is a premature failure which is usually catastrophic. However in civil engineering applications, the structural components are supposed to remain in service for 50 years or more in safety conditions. One argument used to replace steel by polymer-matrix composites is its superior corrosion resistance. Yet stress corrosion of glass fibre $\mathrm{s}$ takes place as soon as moisture reaches the fibre by absorption. This phenomenon accelerates fibre breaking. In most
\end{abstract}


civil engineering applications, glass-fibre reinforced polymers (GRP) are the most common especially because raw material is less expensive.

The lack of full understanding of the fundamental parameters controlling long-term materials performance necessarily leads to over-design and, furthermore, inhibits greater utilization. In this context, lifetime prediction of these structures is an important issue to be solved before wider dissemination of civil engineering applications can take place. As an example, standards dealing with certification of GRP pipes require at least 10000 hours of testing for a high number of specimens. Even though these strong requirements may be foreseen as reasonable, concerning the safety of civil engineering applications, they severely restrict the improvement and innovation of new products.

The present chapter reviews some theoretical approaches for long-term criteria. Timedependent failure criteria will be presented and developed for practical applications and illustrated with experimental cases.

KEYWORDS: Creep; Polymer-Matrix Composites (PMCs); Fatigue; Durability; Damage Accumulation. 


\section{INTRODUCTION}

The structural applications of composite materials in civil construction are becoming more important. One major application is on rehabilitation in renewal of the structural inventory, to repair or strengthen. The success of these applications has promoted the development of new solutions based on FRP (Fibre -Reinforced Polymers). Although these new products may promise a better mechanical performance on a long-term basis, the lack of a historical record prevents its immediate structural optimization. The main reason is because durability factors depend on material systems; usually long-term experimental tests must be performed for each system. Further on, structural designers do not have a full access the all available data since some databases are restricted.

On the other hand the full comprehension of internal material changes from microscopic scale up to the full structure length is far from being known. The interaction between of different mechanisms acting at different scale levels is extremely complex and not yet fully understood. Furthermore many processes affect the durability of a material/structure, defined by Karbhari et al. [1] as "its ability to resist cracking, oxidation, chemical degradation, delamination, wear, and/or the effects of foreign object damage for a specified period of time, under the appropriate load conditions, under specified environmental conditions".

In this chapter we will discuss time dependent failure criteria used to predict lifetime of polymer matrix dominated composites. Although in many structural applications the reinforced fibre are align with principal loading directions, it was verified that for glass fibre -reinforced composites, with fibre volume fraction content of 0.6 , these criteria can 
be applied successfully to predict creep lifetime (Guedes et al. [2]. Obviously the matrix must play an important role in those cases.

In the beginning of the seventies Gotham [3], starting from an idealized failure, tested several polymers at continuous load in tension at $20^{\circ} \mathrm{C}$ to obtain their creep rupture curves and determine a possible ductile-brittle transition. After the experimental results, Gotham [3] concluded that none of the failure curves resemble the idealized curve and most of the failures were ductile. Further he noted that the scatter of data was low and the curves were smooth without discontinuities. Today the existing experimental results for creep rupture of ductile homogeneous materials are very extensive.

As for the PMC's, the published experimental results and theoretical description of creep rupture are not so well documented as for the polymers. This could be explained, in part, by the extremely large variety of material systems offered by the manufacture industry. The other reason is because the systems are naturally very complex, with a great number of boundaries between the constituents, given origin to a large number of local defects, such as debonds and cracks.

According to Reifsnider et al. [4], all creep rupture analyses could be divided into two major categories: the local and direct analysis of the growth of the defects and the global and homogeneous analysis. The late analysis concerns only the summation of all micro-processes effects acting concomitantly and often designated as accumulation or quasi-homogeneous damage models. Of course this category is more promising due to the inherent complexity of the former analysis.

Brüller [5], [6], [7] investigated profoundly the applicability of an energy criterion to model the creep rupture of thermoplastics. He applied the Reiner-Weissenberg (R-W) theory [8] with success to determine the linear viscoleastic limit. For the prediction of 
fracture and crazes, Brüller proposed a modification of the theory, only the total timedependent energy contributed for the creep rupture, provided that the stress level was lower than the static rupture stress, then failure occur when the energy reach a limit value, considered a material property. After this, Brüller establish the conditions for creep and stress relaxation failure, showing some experimental evidence. More recently Theo [9], [10] and Boey [11] presented an application of the R-W criterion to a 3element mechanical model, to describe the creep rupture of polymers. The predictions produced by such creep rupture model were in good agreement with the experimental data for several tested polymers. Further on the model appears to be able to determine the upper stress limit (immediate failure) and lower stress limit (no failure). The drawbacks can be related with a difficult mathematical manipulation of the model, with some eventual difficulties to fit the model into the experimental data and with the uncouple description of creep and creep rupture.

Griffith et al. [12] applied the Zhurkov relationship, to predict the time to rupture of continuous fibre -reinforced plastics with a reasonable success. Dillard [13],[14] determined the creep rupture curves, by fitting experimental data using the classical Larson and Miller and Dorn theories. Dillard developed a numerical model, based on the classical laminate theory, to predict the creep pf general laminates coupled with a lamina failure model based on a modification of the Tsai-Hill theory to include creep rupture curves. After this, failure data at elevated temperatures for several general laminates of T300/934, a carbon fibre /epoxy resin, was compared favourably with numerical predictions; i.e. the predictions were within the same magnitude of the experimental data. Hiel [15] applied the Reiner-Weissenberg criterion to the very same experimental data with some promising results. Latter Raghavan \& Meshii [16], [17] 
presented a creep-rupture model, based on a creep model and a critical fracture criterion, and applied it to a high Tg epoxy and its carbon fibre reinforced composites with good results. These authors found out that the critical fracture energy was dependent on strain rate and temperature. For elevated temperatures or very long times, a constant value for the critical fracture energy was considered suitable, in this case in accordance with the Reiner-Weissenberg criterion.

Miyano et al. [18], [19], [20], [21] showed experimental evidence that flexural and tensile strength of CRFP (Carbon Fibre Reinforced Composite) depend on rate loading and temperature, even near room temperature. It was also proved that time-temperature superposition principle was applicable to obtain master curves for strength of CFRP. Moreover, the same time-temperature superposition principle was applicable for static, creep and fatigue strengths, which presented the same failure mechanism over a wide range of time and temperature.

Since materials are far from being homogeneous, disorder play an important role in strength of materials. Size effects on samples strength are one consequence of this phenomenon. Today, the importance of a statistical treatment in determining the strength of materials is widely recognized. Statistical theories for fracture models are able to describe damage progression and failure in a qualitative manner of real (brittle and quasi-brittle) materials [22]. The designated fibre bundle models (FBM) are one of the simplest approaches used to analyze fracture in disordered media (Alava 2006). Time-dependent fracture was approached by generalizations of FBM. In these models each fibre obeys a time-dependent constitutive law [23]. These models were also extended to interface creep failure [24]. Furthermore experimental results proved that these simple models with a large heterogeneity, based on interaction of representative 
elements with a simple nonlinear rheology, were sufficient to explain qualitatively and quasi-quantitatively the creep failure of composite materials [25],[26]. This research revealed the existence of a stress threshold, under which an infinite lifetime is expected, and that there is a strong correlation between the primary creep and rupture time. Also a strong correlation was found between the time of the minimum of the strain rate in the secondary creep regime and the failure time. A related relationship as found by Little [27] for random continuous fibre mat reinforced polypropylene composite. It was found that the estimated secondary creep rate was inversely related to the observed creep rupture response time [27]. It is to be noted that this is quite similar to the relationship found out for metals by Monkman and Grant [28].

Dealing directly with engineering aspects of the failure problem, statistical models combined with the micro-mechanical analysis have bee used, with success, to model the strength and creep-rupture of fibre composites. Wagner et al. [29] conducted an experimental study on the creep rupture of single Kevlar 49 filaments and concluded that the lifetimes follow a two-parameter Weilbull distribution, as predicted by the theory based on a statistical micro-mechanical model. Later Phoenix et al. [30] developed a statistical model for the strength and creep-rupture of idealized seven carbon fibre composites, combining creep in the matrix and the statistics of fibre strength. The experiments verified the theoretical predictions for the strength but were not very conclusive for the creep rupture, pointing the need for more reliable characterization of the fibre strength, matrix creep and the time-dependent debonding at the fibre matrix interface. More recently Vujosevic et al. [31] developed a micromechanical statistical model to predict the creep and creep rupture of epoxy resins, using a 2D lattice to describe the microstructure and a probabilistic kinetic theory of 
rupture of the molecular chains to characterize the creep deformation evolution. The time to creep failure is defined as the state at which the lattice stiffness reaches a zero value.

All these local and direct analysis of the growth of the defects have shown promising results. This type of analysis has the advantage to allow a deeper understanding of the mechanisms responsible for the rupture and creep-rupture. Nevertheless the global and homogeneous analysis, simpler to formulate and solve, is more appropriated for practical applications. Hiel [15], [32] in fact states that the failure should be a part of a complete constitutive description of the material. Brinson [33] argued that this approach could simplify the procedure to predict the delayed failure in structural polymers without loosing the necessary accuracy. Being failure part of the complete constitutive description of the viscolastic material it is easy to demonstrate that failure criterion benefits from the TTSP and TSSP procedures. These feature are present in the Schapery viscoelastic model [34] [35], for example, which allows the accelerated tests, certainly in accordance with Miyano et al. [20] experimental evidence. Abdel-Tawab and Weitzman [36] developed a model that couples viscoelastic behaviour with damage since in the formulation the thermodynamic force conjugate to damage depends on the viscoelastic internal state variables. It appears to be a good theoretical framework to understand the applicability of TTSP obtained from the viscoelastic properties to the strength.

Usually the strength theories do not include creep to yield or creep to rupture process. Since the stress-strain analysis of is based on Continuum Mechanics it presents a difficulty with predicting failure in general and creep failure in particular of polymers and polymer matrix based composites. Fracture Mechanics and Damage Mechanics 
include the distribution of defects into continuum models, which allow time-dependent failure prediction. Energy-based failure criteria provide another possible approach. For example, establishing that the energy accumulated in the springs of the viscoelastic mechanical model, designated as free energy, has a limit value. This limit can be or not constant. Earlier approaches for the prediction of time dependent failures provide explicit elementary equations to predict lifetime

In the context of the present chapter a global and homogeneous analysis was chosen because it is more appropriated for practical engineering applications.

\section{ENERGY-BASED FAILURE CRITERIA}

One of the first theoretical attempts to include time on a material strength formulation was developed by Reiner and Weissenberg [8], for viscoelastic materials. Briefly, the Reiner-Weissenberg criterion [8] states that the work done during the loading by external forces on a viscoelastic material is converted into a stored part (potential energy) and a dissipated part (loss energy). In summary the criterion says that the instant of failure depends on a conjunction between distortional free energy and dissipated energy, a threshold value of the distortional energy is the governing quantity.

Let us assume that the unidirectional strain response of a linear viscoelastic material, under arbitrarily stress $\sigma(t)$, is given by the power law as,

$$
\varepsilon(t)=D_{0} \sigma(t)+D_{1} \int_{0}^{t}\left(\frac{t-\tau}{\tau_{0}}\right)^{n} \frac{\partial \sigma(\tau)}{\partial \tau} d \tau
$$

where $D_{0}, D_{1}, n$ are material constants; and $\tau_{0}$ represents the time unity (equal to 1 second or 1hour or 1day, etc.). 
The free stored energy, using Hunter [37] formulation, is given by

$$
W_{s}(t)=\varepsilon(t) \sigma(t)-\frac{1}{2} D_{0} \sigma(t)^{2}-\frac{1}{2} \int_{0}^{t} \int_{0}^{t} D_{1}\left(\frac{2 t-\tau_{1}-\tau_{2}}{\tau_{0}}\right)^{n} \frac{\partial \sigma\left(\tau_{1}\right)}{\partial \tau_{1}} \frac{\partial \sigma\left(\tau_{2}\right)}{\partial \tau_{2}} d \tau_{1} d \tau_{2}
$$

The total energy is defined as,

$$
W_{t}(t)=\int_{0}^{t} \sigma(\tau) \frac{\partial \varepsilon(\tau)}{\partial \tau} d \tau
$$

Accordingly these time-dependent failure criteria [38] predict the lifetime under constant load, as a function of the applied load $\sigma_{0}$ and the strength under instantaneous condition $\sigma_{\mathrm{R}}$ :

Reiner-Weissenberg Criterion $(\mathrm{R}-\mathrm{W})$, states that $W_{s}(t) \leq \frac{D_{0}}{2} \sigma_{R}{ }^{2}$,

$$
\left(\frac{t_{f}}{\tau_{0}}\right)=\left(\frac{1}{2-2^{n}}\right)^{\frac{1}{n}}\left(\frac{D_{0}}{D_{1}}\right)^{\frac{1}{n}}\left(\frac{1}{\gamma}-1\right)^{\frac{1}{n}}
$$

Maximum Work Stress Criterion (MWS), states that $W_{t}(t) \leq \frac{D_{0}}{2} \sigma_{R}{ }^{2}$,

$$
\left(\frac{t_{f}}{\tau_{0}}\right)=\left(\frac{1}{2} \frac{D_{0}}{D_{1}}\right)^{\frac{1}{n}}\left(\frac{1}{\gamma}-1\right)^{\frac{1}{n}}
$$

Maximum Strain Criterion (MS), states that $\varepsilon(t) \leq D_{0} \sigma_{R}$,

$$
\left(\frac{t_{f}}{\tau_{0}}\right)=\left(\frac{D_{0}}{D_{1}}\right)^{\frac{1}{n}}\left(\frac{1}{\sqrt{\gamma}}-1\right) \frac{1}{n}
$$

Modified Reiner-Weissenberg Criterion (MR-W), states that $W_{t}(t) \leq\left(\frac{D_{0}}{2} \sigma_{R}\right) \sigma(t)$,

$$
\left(\frac{t_{f}}{\tau_{0}}\right)=\left(\frac{1}{2-2^{n}}\right)^{\frac{1}{n}}\left(\frac{D_{0}}{D_{1}}\right)^{\frac{1}{n}}\left(\frac{1}{\sqrt{\gamma}}-1\right)^{\frac{1}{n}}
$$


where $\gamma=\sigma_{0}^{2} / \sigma_{R}^{2}$.

If we consider the normalized rupture free energy as

$$
\bar{w}_{f}=\frac{w_{f}}{\frac{D_{0}}{2} \sigma_{R}{ }^{2}},
$$

and the normalized applied stress as

$$
\bar{\sigma}_{0}=\frac{\sigma_{0}}{\sigma_{R}},
$$

then it is possible to rewrite all the previous criteria in an non-dimensional form.

Reiner-Weissenberg Criterion (R-W):

$\bar{w}_{f}=1$.

Maximum Work Stress Criterion (MWS):

$\bar{w}_{f}=2^{n} \bar{\sigma}_{0}^{2}+\left(1-2^{n-1}\right)$.

Maximum Strain Criterion (MS):

$\bar{w}_{f}=\left(2^{n}-1\right) \bar{\sigma}_{0}^{2}+\left(2-2^{n}\right) \bar{\sigma}_{0}$.

Modified Reiner-Weissenberg Criterion (MR-W):

$\bar{w}_{f}=\bar{\sigma}_{0}$.

This relationships a linear viscoelastic material with $\mathrm{n}=0.3$ are plotted in figure 1 . 


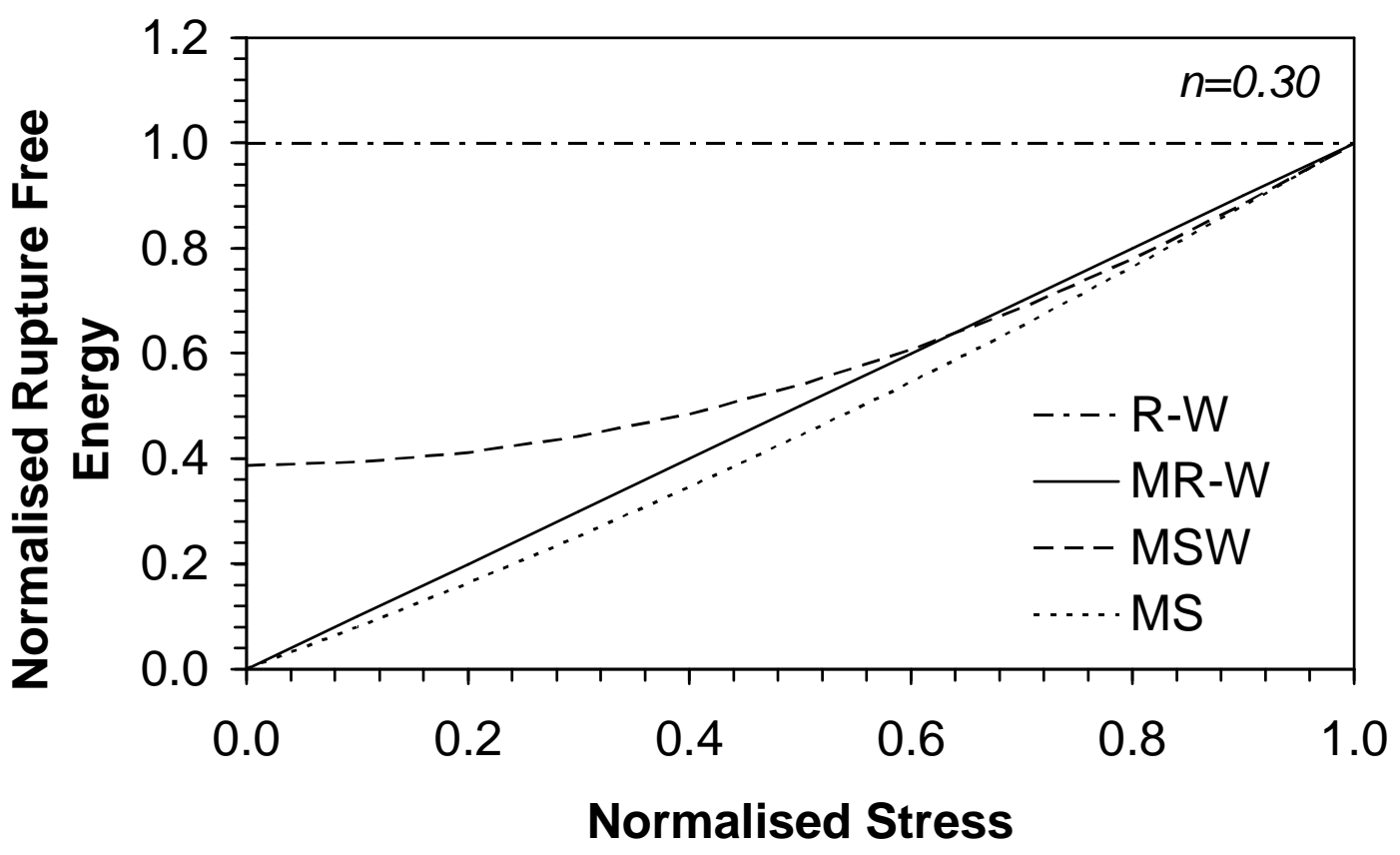

Figure 1: Comparison of failure criteria for a linear viscoelastic material with $n=0.3$.

In summary these approaches establish a relationship between time to failure, viscoelastic properties and static stress failure throughout a stored elastic energy limit concept. As an approximation it is not difficult to conclude that we can take $t \sim \sigma^{-2 / \mathrm{n}}$ for the $\mathrm{R}-\mathrm{W}$ and the MSW criteria and $t \sim \sigma^{-1 / \mathrm{n}}$ for the MS and the MR-W criteria. Similar results were obtained by using fracture mechanics concepts [39]. In fact these concepts established a relationship between time to failure, viscoelastic properties and strength properties [40]; [41], which are similar to the present approach. The main difference in these failure criteria is the interpretation of the physical constants. According to Song et al. [42] there are three major phenomena, which frequently occur simultaneously, responsible for creep failure of viscoelastic materials: (1) time-dependent constitutive equations; (2) time to the formation of overstressed polymer chains in a localized plastic area, i.e. fracture initiation mechanism; (3) the kinetics of molecular flow and bond 
rupture of the overstressed polymer chains. The facture mechanics approach assumes the existence of defects from the start and develops a theory about the kinetic crack growth, i.e. the fracture initiation process is neglected. In the present approach the stored energy in the material, i.e. the energy stored by all springs in the viscoelastic model, can be compared with energy necessary to stretch the polymer chains and promote their bond rupture. In fact it is possible to visualize the polymer chains as linear springs acting as energy accumulators. Nevertheless these energy accumulators have a limited capacity above which bond rupture is verified. Therefore the stored energy limit, denominated critical energy, can be related with energy involved in all microscale bond ruptures that lead to creep-rupture. Most probability this critical energy depends on the internal state. In reality, there are some experimental indications that this critical energy is temperature and strain-rate dependent [16], at least for temperatures lower than the glass transition temperature $T g$ (or shorter times). This is in accordance with results obtained in this work, i.e. the R-W criterion is not universal. On the other hand there is some experimental evidence, for polymers and composite polymers, that change in fracture mode is a result of change in critical energy with temperature and strain rate [16]. Finally, it is not difficult to accept that creep-rupture is strongly related with creep compliance or relaxation modulus. This relationship comes out naturally from theoretical approaches like fracture mechanics and energy criteria. Furthermore creep-rupture and relaxation modulus variations with time, measured experimentally, resemble in an extraordinary manner. Most probably this signifies that a change in the relaxation modulus corresponds to a change in the strength. 


\section{CREEP RUPTURE BASED ON SIMPLE MICROMECHANICAL MODELS}

In this section are described two simple micromechanical models that are used to simulate creep-rupture of unidirectional composites by assuming that the matrix is a vsicoelastic material and the fibre is an elastic material or by assuming that both constituents are viscoelastic solids. The results for both models are compared with energy failure criteria for illustration purposes.

Du and McMeeking [43] predicted the creep rupture time in unidirectional composites under tensile loads. The model assumed that when the composite strain (or stress) of the McLean [44] model had reached the rupture strain (or stress) of the Curtin [45] model, the composite failed. Latter on Koyanagi et al. [46] proposed a modified version applied to a unidirectional glass fibre /vinylester composite, which was in part experimentally validated.

This simple model can be used to illustrate some aspects of creep failure. Following Du and McMeeking [43] and Koyanagi et al. [46] the Curtin-McLeen model (CML) lifetime expressions are deduced for creep loading condition. The McLeean model was derived considering the fibre was elastic and the matrix was viscoleastic;

The fibre strain is (elastic).

$\varepsilon=\frac{\sigma_{f}}{E_{f}}$,

and the matrix strain (viscoelastic).

$\dot{\varepsilon}=\frac{\dot{\sigma}_{m}}{E_{m}}+B \sigma_{m}{ }^{n}$, 
where $\varepsilon$ is the total strain, $B$ and $n$ the creep coefficients, $\sigma_{m}$ the matrix stress, $\sigma_{f}$ the fibre stress, and $E_{m}, E_{f}$ are the matrix and fibre modulus, respectively.

The composite stress is given by the rule of mixtures,

$\sigma=\left(1-V_{f}\right) \sigma_{m}+V_{f} \sigma_{f}$

where $V_{f}$ is the fibre volume fraction. From the above equations the composite strain

under creep load $\sigma=\sigma_{0}$ is derived.

$\varepsilon(t)=\frac{\sigma_{0}}{V_{f} E_{f}}-\frac{1-V_{f}}{V_{f} E_{f}}\left(\left(\frac{E_{m}}{\left(1-V_{f}\right) E_{m}+V_{f} E_{f}} \sigma_{0}\right)^{1-n}+B \frac{(n-1) V_{f} E_{m} E_{f}}{\left(1-V_{f}\right) E_{m}+V_{f} E_{f}} t\right)^{1 /(1-n)}$.

The initial creep strain is

$\varepsilon(0)=\frac{1}{\left(1-V_{f}\right) E_{m}+V_{f} E_{f}} \sigma_{0}$.

In this model the creep strain is limited to a defined value,

$\lim _{t \rightarrow \infty} \varepsilon(t)=\frac{\sigma_{0}}{V_{f} E_{f}}$

Assuming the allowable maximum fibre stress as

$\varepsilon_{\text {max }}=\frac{S_{\text {max }}}{E_{f}}$,

the creep lifetime expression is obtained.

$t_{c}=\frac{\left(1-V_{f}\right) E_{m}+V_{f} E_{f}}{(1-n) V_{f} E_{m} E_{f} B}\left[\left(\frac{1-V_{f}}{\sigma_{0}-V_{f} S_{\max }}\right)^{n-1}+\left(\frac{\left(1-V_{f}\right) E_{m}+V_{f} E_{f}}{\sigma_{0} E_{m}}\right)^{n-1}\right]$. 
Now it is possible to determine the limit stress level, $\sigma_{S}$, under which the condition for an infinity life-time under creep is verified, which is given by

$$
\sigma_{S}=V_{f} S_{\max }
$$

The general behavior of polymers under the effect of the time, changing from glassy to rubbery state, i.e. deform in an asymptotic way as Brinson [33] recently discussed in detail. This response is in accordance with the features displayed by the CML model. The creep master curve of typical polymers reaches a plateau after a certain temperature level or equivalent time, by applying the Time-Temperature-Superposition-Principle (TTSP). Therefore the simple power law cannot capture the long term range creep behavior. Furthermore it is expected that the rupture stress becomes constant in the rubbery plateau region of the polymer. Following Yang's [47] research, a variation of the usual generalized power based on the Cole-Cole function is used to model the creep strain under arbitrarily stress $\sigma(t)$ as,

$$
\varepsilon(t)=D_{0} \sigma(t)+\int_{0}^{t} \frac{D_{\infty}-D_{0}}{1+\left(\frac{\tau_{0}}{t-\tau}\right)^{n}} \frac{\partial \sigma(\tau)}{\partial \tau} d \tau,
$$

where $D_{0}, D_{\infty}, n$ are material constants and $\tau_{0}=f(\sigma)$. For a constant applied stress, i.e. a creep load, the equation becomes

$$
\varepsilon(t)=D_{0} \sigma_{0}+\frac{D_{\infty}-D_{0}}{1+\left(\frac{\tau_{0}}{t}\right)^{n}} \sigma_{0},
$$

It is very easy to demonstrate that if we apply the maximum strain at failure criterion $\varepsilon_{\max }=D_{0} \sigma_{R}$ the following lifetime expression is obtained 
$\frac{t_{f}}{\tau_{0}}=\left[\frac{D_{0}\left(\sigma_{R}-\sigma_{0}\right)}{\left(D_{\infty}-D_{0}\right) \sigma_{0}-D_{0}\left(\sigma_{R}-\sigma_{0}\right)}\right]^{1 / n}$.

As before it is possible to determine the limit stress level, $\sigma_{S}$, under which the condition for an infinite lifetime under creep is verified, which is given by

$$
\sigma_{S}=\frac{D_{0}}{D_{\infty}} \sigma_{R}
$$

Since in the CML model we have the following relationships

$$
D_{0}=\frac{1}{\left(1-V_{f}\right) E_{m}+V_{f} E_{f}}, D_{\infty}=\frac{1}{V_{f} E_{f}}, \sigma_{R}=\frac{S_{\max }}{E_{f}}\left[\left(1-V_{f}\right) E_{m}+V_{f} E_{f}\right] .
$$

By applying the expression (26) we obtain the following,

$$
\sigma_{S}=\frac{\frac{1}{\left(1-V_{f}\right) E_{m}+V_{f} E_{f}}}{\frac{1}{V_{f} E_{f}}} \frac{S_{\max }}{E_{f}}\left[\left(1-V_{f}\right) E_{m}+V_{f} E_{f}\right]=V_{f} S_{\max } .
$$

This coincides with the previous result given by expression (22).

In order to illustrate the previous results a numerical example is give. In table 1 are given the CML parameters used.

Table 1: Elastic and viscoelastic CML parameters used to simulate a unidirectional composite.

\begin{tabular}{ccccccc}
\hline $\begin{array}{c}E_{f} \\
(\mathrm{MPa})\end{array}$ & $\begin{array}{c}E_{m} \\
(\mathrm{MPa})\end{array}$ & $V_{f}$ & $\begin{array}{c}E_{c} \\
(\mathrm{MPa})\end{array}$ & $\begin{array}{c}B \\
1 / \text { hour }\end{array}$ & $n$ & $\begin{array}{c}S_{\max } \\
(\mathrm{MPa})\end{array}$ \\
\hline 70200 & 10000 & 0.05 & 13010 & $2.50 \mathrm{E}-10$ & 2.5 & 1100 \\
\hline
\end{tabular}

The creep compliance for the CML is depicted in Figure 2. The non-linearity effect is very pronounced in this case. 


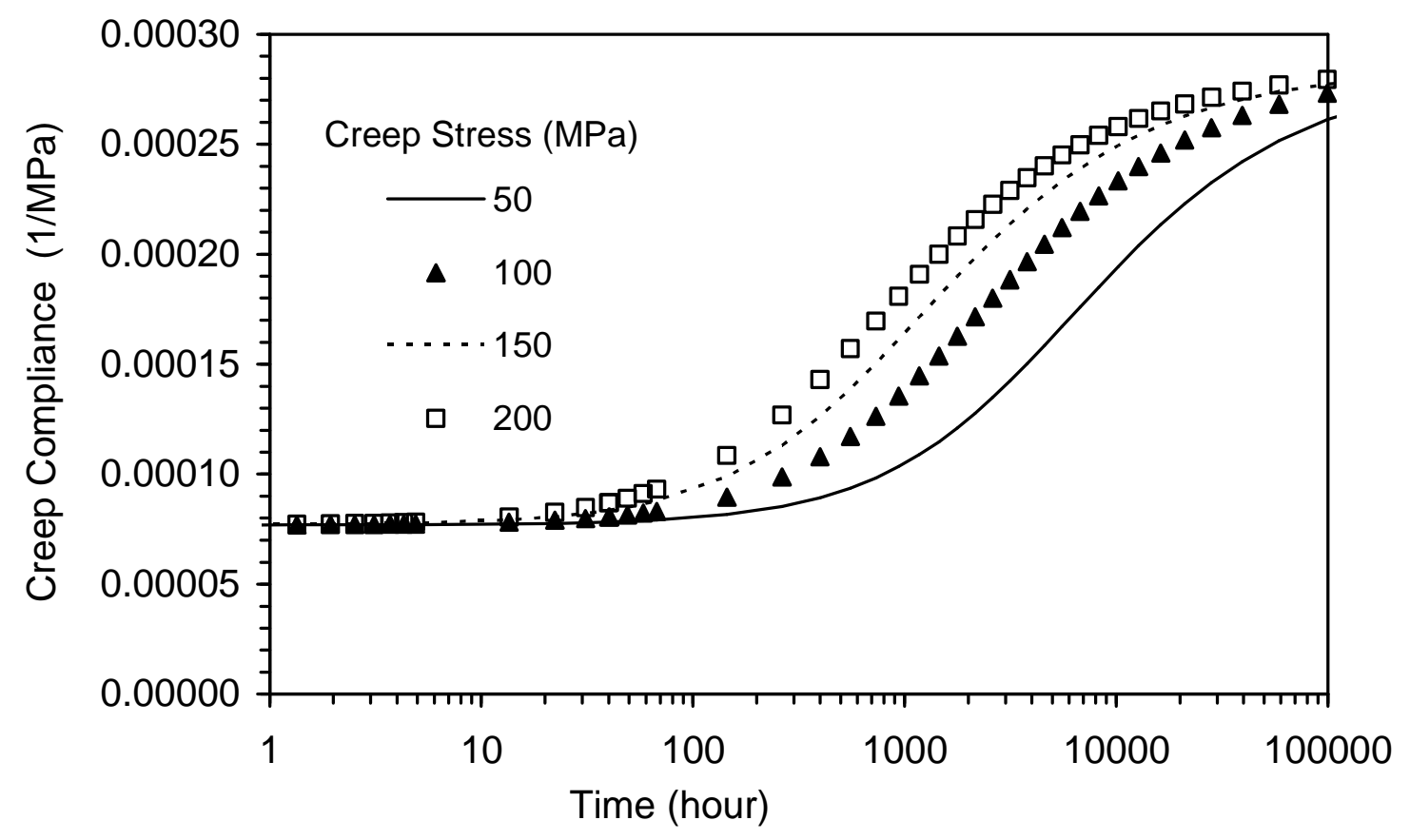

Figure 2: Creep compliance obtained for the simulated unidirectional composite using the CML model.

From creep data obtained from the CML model, a nonlinear viscoelastic power law was fitted. The parameters are presented in Table2.

Table 2: General power law parameters fitted to the simulated unidirectional composite.

\begin{tabular}{cccc}
\hline $\begin{array}{c}D_{0} \\
(1 / \mathrm{GPa})\end{array}$ & $\begin{array}{c}D_{\infty} \\
(1 / \mathrm{GPa})\end{array}$ & $n$ & $\begin{array}{c}\sigma_{R} \\
(\mathrm{MPa})\end{array}$ \\
\hline 0.0769 & 0.287 & 0.800 & 204 \\
\hline$\tau_{0}=2.54 .10^{6} \sigma^{-1.47}$ & &
\end{tabular}

Using the viscoelastic parameters in the lifetime expression presented before, its predictions were compare with CML calculated lifetime. The results are depicted in Figure 3. 


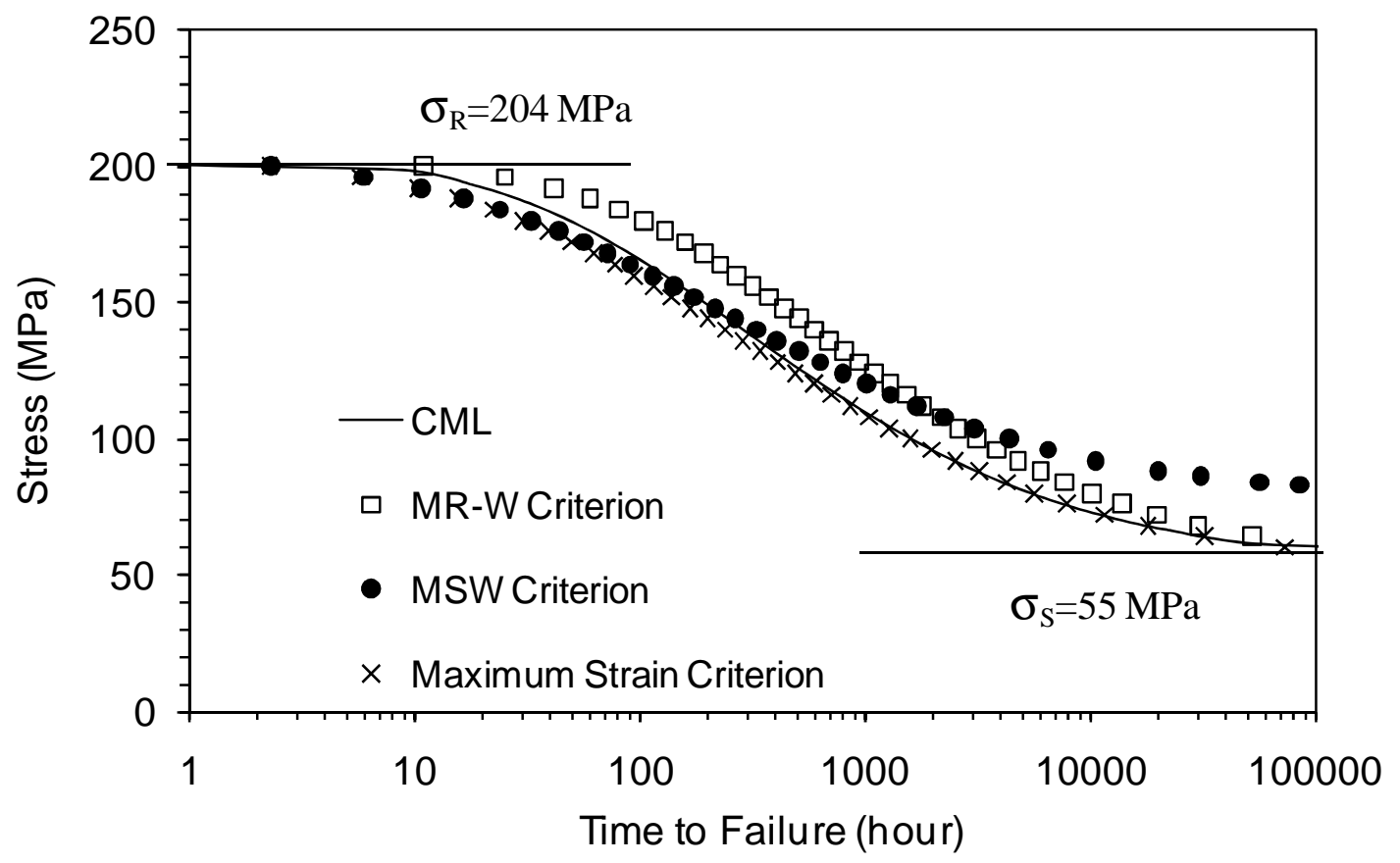

Figure 3: Calculated lifetime for the simulated unidirectional composite using the CML model.

As it would be expected the MS criterion give the best approach the CML lifetime results, since the model uses the fibre maximum strain as failure criterion. Nevertheless the other time dependent failure criteria are capable to predict quite close the CML lifetime and predict the stress limit for infinite lifetime.

Let us now considered a variation of the previous model designated, from now on, as Modified Curtin-McLeen model (MCML). In this case the fibre and the matrix are considered viscoelastic;

The fibre strain is (viscoelastic),

$\dot{\varepsilon}=\frac{\dot{\sigma}_{f}}{E_{f}}+H \sigma_{f}^{p}$, 
and the matrix strain (viscoelastic),

$\dot{\varepsilon}=\frac{\dot{\sigma}_{m}}{E_{m}}+B \sigma_{m}{ }^{n}$,

where $\varepsilon$ is the total strain, $B, H, n$ and $p$ the creep coefficients, $\sigma_{m}$ the matrix stress, $\sigma_{f}$ the fibre stress, and $E_{m}, E_{f}$ are the matrix and fibre modulus, respectively.

The composite stress is given by the rule of mixtures,

$\sigma=\left(1-V_{f}\right) \sigma_{m}+V_{f} \sigma_{f}$

where $V_{f}$ is the fibre volume fraction. From the above equations the following

differential equation is derived, considering the creep loading condition $\sigma_{0}=$ constant,

$$
\frac{\left(1-V_{f}\right) E_{m}+V_{f} E_{f}}{\left(1-V_{f}\right) E_{m} E_{f}} \dot{\sigma}_{f}+H \sigma_{f}{ }^{p}-B\left[\frac{\sigma_{0}-V_{f} \sigma_{f}}{\left(1-V_{f}\right)}\right]^{n}=0
$$

The differential equation can be analytically integrated provided that $n=p=2$. In that condition the solution is readily obtained with the initial condition

$\sigma_{f}(0)=\frac{E_{f}}{E_{m}\left(1-V_{f}\right)+E_{f} V_{f}} \sigma_{0}$

Integrating

$\sigma_{f}(t)=\frac{-B V_{f}+\left(1-V_{f}\right) \sqrt{B H} \tanh \left(\frac{E_{f} E_{m} \sqrt{B H}}{V_{f} E_{f}+E_{m}\left(1-V_{f}\right)}(t+K) \sigma_{0}\right)}{H\left(1-V_{f}\right)^{2}-B V_{f}^{2}} \sigma_{0}$,

where 
$K=-\frac{E_{f} V_{f}+E_{m}\left(1-V_{f}\right)}{E_{f} E_{m} \sqrt{B H}} \frac{1}{2 \sigma_{0}}(\ln |1+Z|-\ln |-1+Z|)$,

with $Z=\frac{B E_{m} V_{f}+E_{f} H\left(1-V_{f}\right)}{\left(E_{m}\left(1-V_{f}\right)-E_{f} V_{f}\right) \sqrt{B H}}$.

Assuming the allowable maximum fibre stress as,

$\sigma_{f}\left(t_{R}\right)=S_{\max }$,

and assuming that $B \gg H$ the creep lifetime is obtained,

$t_{R}=\frac{V_{f} E_{f}+E_{m}\left(1-V_{f}\right)}{2 E_{f} E_{m} \sqrt{B H} \sigma_{0}}(\ln |1+Y|-\ln |-1+Y|)-K$,

with $Y=\frac{S_{\max }\left[B V_{f}^{2}-H\left(1-V_{f}\right)^{2}\right]-B V_{f} \sigma_{0}}{\left(1-V_{f}\right) \sqrt{B H} \sigma_{0}}$.

In this case for $t_{R} \rightarrow \infty$ we must have

$\frac{S_{\max }\left[B V_{f}^{2}-H\left(1-V_{f}\right)^{2}\right]-B V_{f} \sigma_{0}}{\left(1-V_{f}\right) \sqrt{B H} \sigma_{0}} \rightarrow 1$

Therefore the creep stress under which the condition of an infinite lifetime is verified is obtained

$\sigma_{S} \rightarrow \frac{S_{\max }\left[B V_{f}^{2}-H\left(1-V_{f}\right)^{2}\right]}{B V_{f}-\left(1-V_{f}\right) \sqrt{B H}}$

In conclusion the applied stress range which provokes creep failure $\sigma_{S}<\sigma_{0}<\sigma_{R}$ is

$$
\frac{S_{\max }\left[B V_{f}^{2}-H\left(1-V_{f}\right)^{2}\right]}{B V_{f}-\left(1-V_{f}\right) \sqrt{B H}}<\sigma_{0}<\frac{S_{\max }}{E_{f}}\left[E_{m}\left(1-V_{f}\right)+E_{f} V_{f}\right]
$$


Therefore it can be concluded that although the MCML model exhibits an unbound creep strain the creep failure stresses is bounded due to the fibre relaxation.

In order to illustrate the previous results a numerical example follows. In table 3 are given the MCML parameters used.

Table 3: Elastic and viscoelastic MCML parameters used to simulate a unidirectional composite.

\begin{tabular}{ccccccccc}
\hline $\begin{array}{c}E_{f} \\
(\mathrm{MPa})\end{array}$ & $\begin{array}{c}E_{m} \\
(\mathrm{MPa})\end{array}$ & $V_{f}$ & $\begin{array}{c}E_{c} \\
(\mathrm{MPa})\end{array}$ & $\begin{array}{c}B \\
1 / \text { hour }\end{array}$ & $n$ & $\begin{array}{c}S_{\max } \\
(\mathrm{MPa})\end{array}$ & $\begin{array}{c}H \\
1 / \text { hour }\end{array}$ & $p$ \\
\hline 70200 & 10000 & 0.05 & 13010 & $2.50 \mathrm{E}-10$ & 2 & 1100 & $2.50 \mathrm{E}-13$ & 2 \\
\hline
\end{tabular}

The creep compliance for the MCML is depicted in Figure 4. The non-linearity effect is also very pronounced in this case.

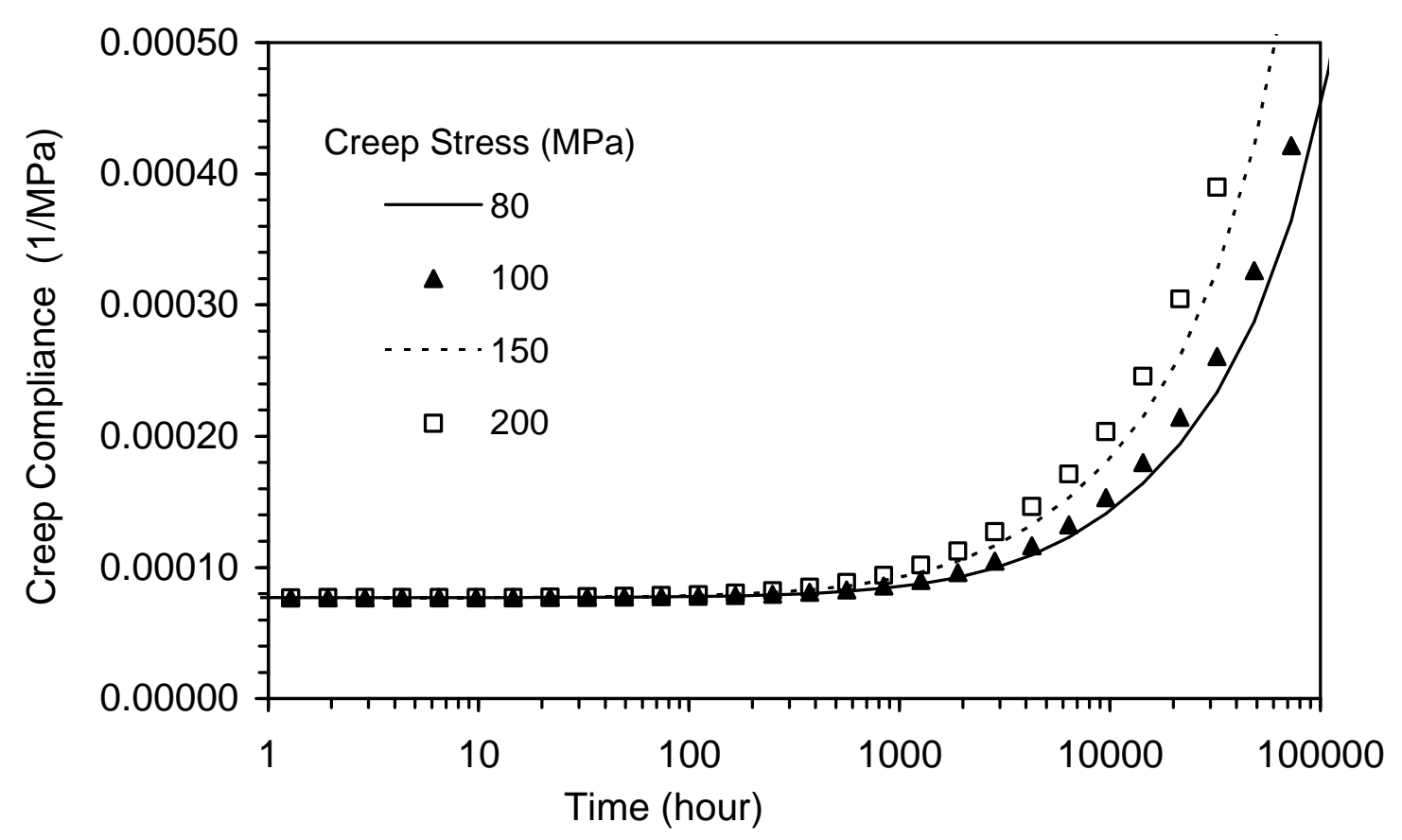


Figure 4: Creep compliance obtained for the simulated unidirectional composite using the MCML model.

From creep data obtained from the MCML model, a nonlinear viscoelastic power law was fitted. The parameters are presented in Table4.

Table 4: General power parameters fitted to the simulated unidirectional composite.

\begin{tabular}{|c|c|c|c|}
\hline $\begin{array}{c}D_{0} \\
(1 / \mathrm{GPa})\end{array}$ & $\begin{array}{c}C \\
(1 / \mathrm{GPa})\end{array}$ & $n$ & $\begin{array}{c}\sigma_{R} \\
(\mathrm{MPa})\end{array}$ \\
\hline 0.0769 & 0.0000440 & 0.790 & 204 \\
\hline
\end{tabular}

As done previously, using the viscoelastic parameters in the lifetime expressions presented before, its predictions were compare with MCML calculated lifetime. The results are depicted in Figure 5.

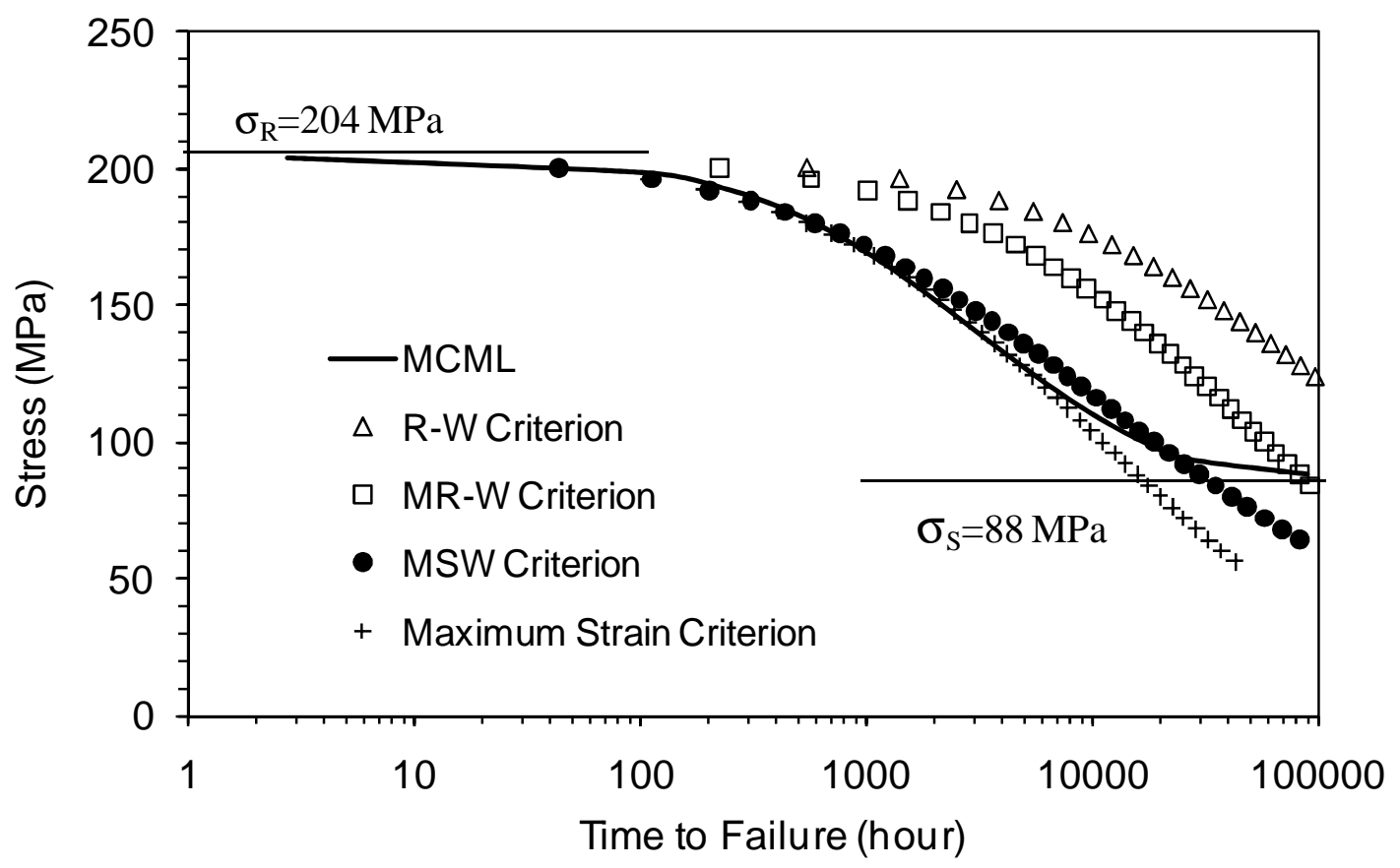


Figure 5: Calculated lifetime for the simulated unidirectional composite using the MCML model.

Again, as it would be expected the MS criterion give the best approach the MCML lifetime results, since the model also uses the fibre maximum strain as failure criterion. The other failure criterion that is capable to quite close the MCML lifetime is the MSW criterion. The other failure criteria fail largely to predict the MCML lifetime. However non of the failure criteria fail to predict the stress limit for infinite lifetime, since all predict creep failure for all applied creep stress levels.

Although both presented micromechanical models are very simple they give us an insight of what are the possible mechanics which lead to creep failure of unidirectional fibre reinforced composites.

\section{EXPERIMENTAL CASES}

The purpose of this section is to give several practical examples that show the applicability of the previous time-dependent failure criteria. These examples were divided into 3 different groups. The first one gather two thermoplastic polymers polyamide (or nylon) and polycarbonate used for technical applications. The second gather representative thermoset composite systems used to produce large structural automotive components. Finally the last group uses creep lifetime experimental data of thermoset composite systems obtained from an accelerated methodology based on the time-temperature superposition principle (TTSP). 


\section{Thermoplastics}

The experimental results for thermoplastics, taken from the technical literature [48], [49], are used to illustrate the present discussion. The materials examined were polyamide 66 (Nylon 66 A100) unfilled, polyamide 66 filled with 30\% of glass fibre (Nylon 66 A190) [48] at room temperature and polycarbonate (PC Lexan 141) at room temperature [49]. These materials were chosen by two reasons; firstly they are already characterized in terms of creep and creep rupture; secondly, as Gotham [3] demonstrated experimentally, the Nylon 66 A100 and PC Lexan 141 present a ductile failure at room temperature and the Nylon 66 A190 a brittle failure. Considering that the materials behavior is linear viscoelastic, which is an approximation for the higher stress levels, the material parameters were determined for the general power law model and presented in Table 5.

Table 5: Viscoelastic and rupture parameters of the polymers materials.

\begin{tabular}{cccccccccccc}
\hline \multirow{2}{*}{ Material } & \multirow{2}{*}{ Ref. } & $\mathrm{T}$ & \multicolumn{3}{c}{ Creep Compliance (1/MPa) } & \multicolumn{3}{c}{ Static Failure $\sigma_{\mathrm{R}},(\mathrm{MPa})$} \\
\cline { 6 - 11 } & $\left({ }^{\circ} \mathrm{C}\right)$ & $\mathrm{D}_{0}$ & $\mathrm{D}_{1}$ & $\mathrm{n}$ & $\tau_{0}$ & $\mathrm{R}-\mathrm{W}$ & $\mathrm{MR}-\mathrm{W}$ & $\mathrm{MWS}$ & $\mathrm{MS}$ \\
\hline Nylon 66 A100 & $\begin{array}{c}\text { Moulding Powders } \\
\text { Group (1974) }\end{array}$ & $23^{\circ}$ & $3.36 \mathrm{E}-04$ & $2.31 \mathrm{E}-05$ & 0.399 & 1 hour & 77 & 77 & 77 & 77 \\
Nylon 66 A190 & $\begin{array}{c}\text { Moulding Powders } \\
\text { Group (1974) }\end{array}$ & $23^{\circ}$ & $1.05 \mathrm{E}-04$ & $6.77 \mathrm{E}-06$ & 0.294 & 1 hour & 95 & 95 & 95 & 95 \\
PC Lexan 141 & Challa (1995) & $23^{\circ}$ & $3.12 \mathrm{E}-04$ & $1.44 \mathrm{E}-04$ & 0.085 & 1 hour & 75 & 89 & 89 & 86 \\
\hline
\end{tabular}

The creep compliance of polyamide 66 displays a linear behavior for times lower than 100 hours. For longer times there is no information for the higher stress levels but we should expect a certain level of nonlinearity. Nevertheless, the impact of higher stress on creep failure prediction for longer times decreases as time increases, which minimizes the possible influence of the nonlinear behavior. The same could be said 
about the other two materials. The rupture stresses, $\sigma_{R}$, were also determined for each material and criterion. This can be done by backward calculation over the experimental results for the higher stress levels and lowest times of the failure data. In practical cases these rupture stresses are not necessarily coincident with static rupture stresses. Sometimes they are not even equal for all the criteria, as in the case of polycarbonate, depending on the creep compliance.

The results are depicted in the following Figures 6-8. In general the predictions are close to the experimental data. However as it can be observer, each material follows a different time-dependent criteria.

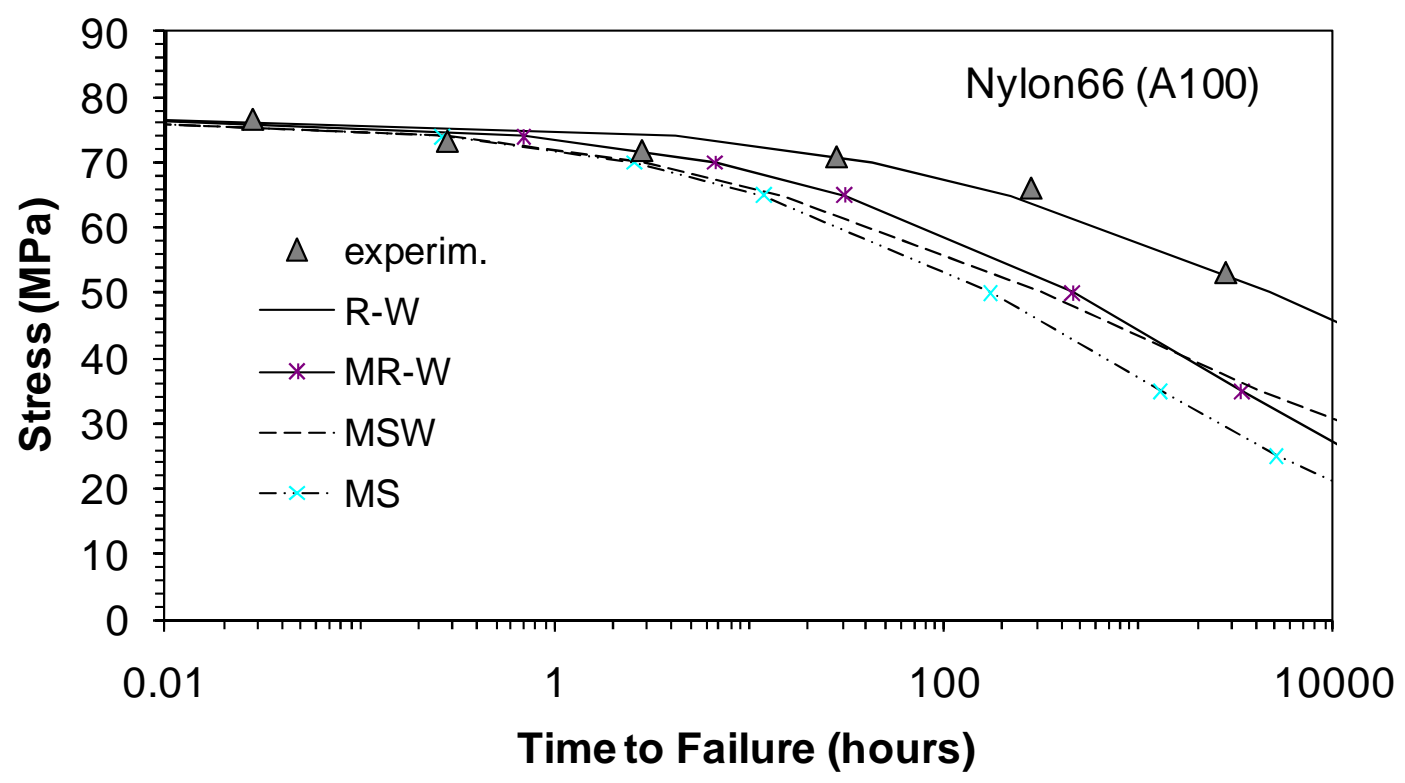

Figure 6: Experimental and calculated creep lifetime for Nylon66 (A100) at room temperature. 


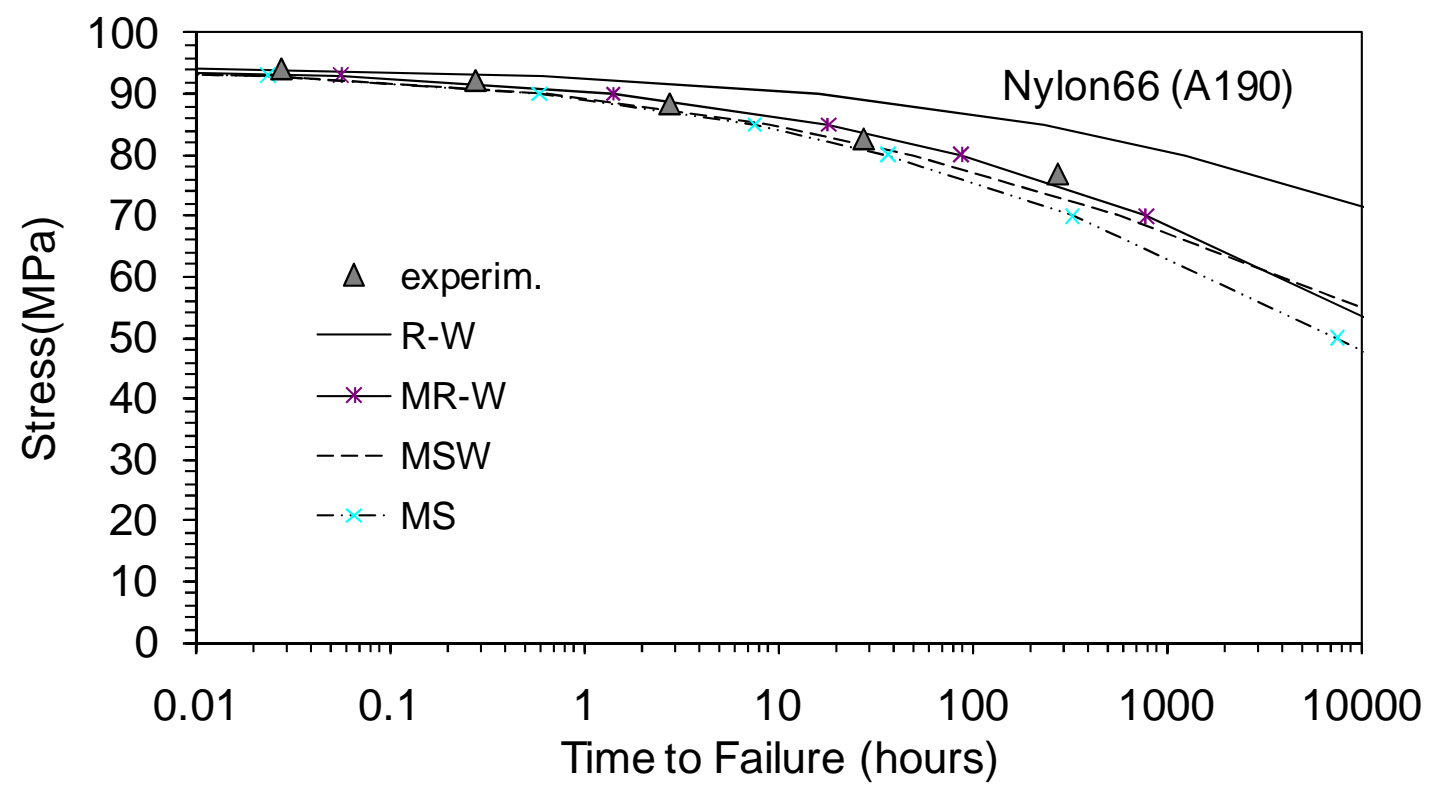

Figure 7: Experimental and calculated creep lifetime for Nylon66 (A190) at room temperature.

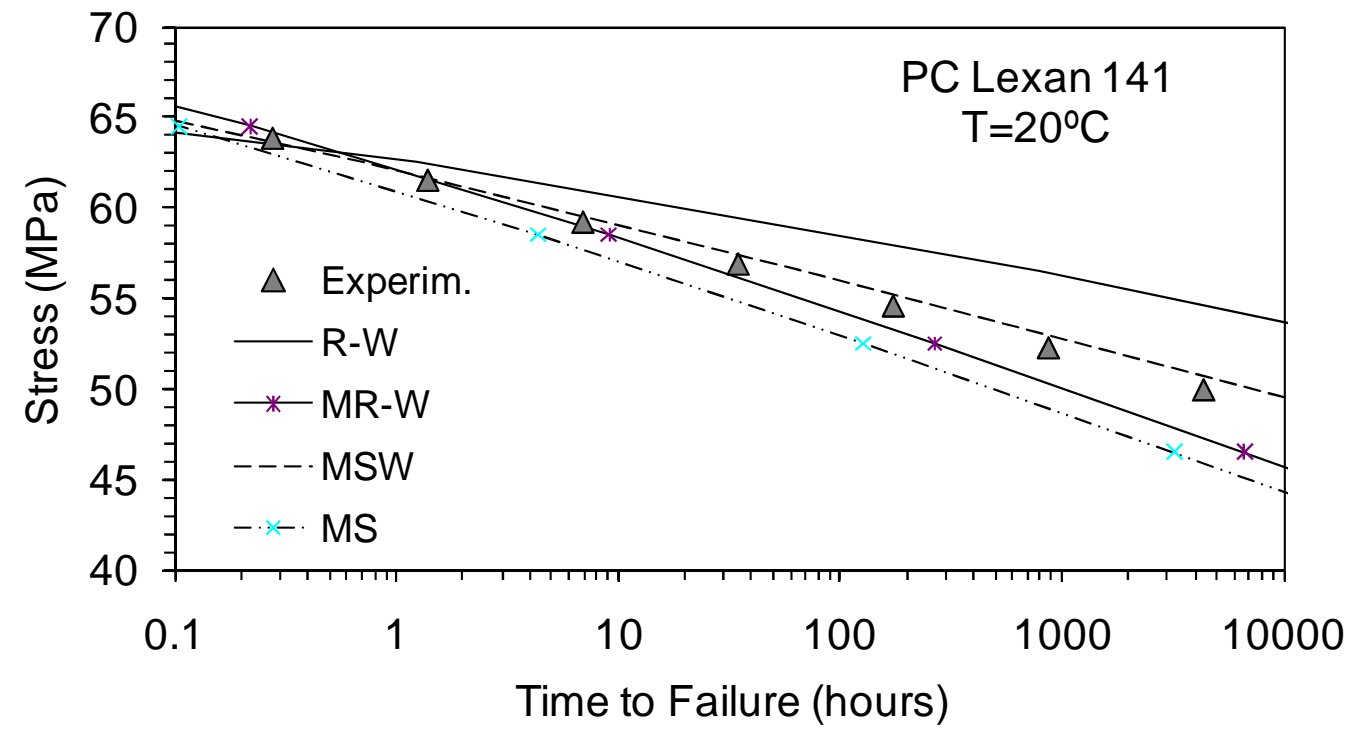

Figure 8: Experimental and calculated creep lifetime for PC Lexan 141. 
As discussed before, it is not difficult to accept that creep-rupture is strongly related with creep compliance or relaxation modulus. This relationship comes out naturally from theoretical approaches like fracture mechanics and energy criteria. Furthermore creep-rupture and relaxation modulus variations with time, measured experimentally, resemble in an extraordinary manner. Most probably this signifies that a change in the relaxation modulus corresponds to a change in the strength. However, the present approach presents some problems and unsolved questions. In the present analysis it was assumed that effect of the non-linear viscoelastic behavior was negligible and apparently the experimental results confirmed that assumption. Nevertheless, a deeper analysis of the impact of non-linear viscoelastic behavior on the creep-rupture predictions is required. For extrapolation purposes a methodology is necessary to determine, from the available creep-rupture data, which approach is appropriated and how long could go that extrapolation. From the present cases it appears that a minimum of $100 \mathrm{~h}$ of creep-rupture data is necessary to choose the appropriate theoretical model in order to extrapolate data almost two decades with a good accuracy. In the present work, one crystalline polymer (polyamide 66) and another non-crystalline polymer (polycarbonate) were used to access theoretical models. In all cases, except for glass fibre reinforced polyamide 66, ductile failure was observed. Apparently these energy based criteria can be applied to different types of polymers with ductile or brittle failures.

\section{Thermosetting Polymer-based Composites}

Experimental results obtained from literature, for thermosetting Polymer-based Composites, are compared with theoretical lifetime predictions,. The viscoelastic 
properties of these materials are displayed in Table 6. The experimental data was obtained from the project conduct by the Oak Ridge National laboratory [50], [51], [52], [53], [54], [55] to develop experimentally based, durability-driven design guidelines to assure the long-term integrity of representative thermoset composite systems to be used to produce large structural automotive components. These examples include different types of reinforcements; E glass fibre randomly orientated chopped strands and continuous strand, swirl-mat fibre and continuous T300 carbon fibre.

Table 6: Viscoelastic and rupture parameters of the composite materials.

\begin{tabular}{|c|c|c|c|c|c|c|c|}
\hline \multirow{2}{*}{ Material } & \multirow{2}{*}{ Ref. } & \multirow{2}{*}{$\begin{array}{c}\mathrm{T} \\
(\stackrel{\circ}{\circ})\end{array}$} & \multicolumn{4}{|c|}{ Creep Compliance (1/MPa) } & \multirow{2}{*}{$\begin{array}{c}\begin{array}{c}\text { Static } \\
\text { Failure } \\
\text { (MPa) }\end{array} \\
\sigma_{R} \\
\end{array}$} \\
\hline & & & $\mathrm{D}_{0}$ & $D_{1}$ & $\mathrm{n}$ & $\tau_{0}$ & \\
\hline $\begin{array}{l}\text { Chopped-Glass-Fibre / } \\
\text { Urethane }\end{array}$ & Corum (2001a) & $23^{\circ}$ & 8.47E-05 & 9.59E-06 & 0.141 & 1hour & 160 \\
\hline Glass-Fibre /Urethane & $\begin{array}{l}\text { Corum(1998), } \\
\text { Ren(2002a, 2002b) }\end{array}$ & $23^{\circ}$ & $1.06 \mathrm{E}-04$ & 7.35E-06 & 0.196 & 1hour & 120 \\
\hline Glass-Fibre /Urethane & $\begin{array}{l}\text { Corum (1998), } \\
\text { Ren(2002a, 2002b) }\end{array}$ & $120^{\circ}$ & $1.06 \mathrm{E}-04$ & 1.37E-05 & 0.196 & 1hour & 85 \\
\hline Crossply Carbon-Fibre $\pm 45^{\circ}$ & Corum (2001b) & $23^{\circ}$ & 8.85E-05 & 2.04E-08 & 0.200 & 1hour & 140 \\
\hline Crossply Carbon-Fibre $90^{\circ} / 0^{\circ}$ & Corum (2001b) & $23^{\circ}$ & 2.14E-05 & 8.30E-07 & 0.112 & 1hour & 455 \\
\hline Quasi-Isotropic Carbon-Fibre & Corum(2002) & $23^{\circ}$ & 3.09E-05 & 7.96E-07 & 0.161 & 1hour & 295 \\
\hline Quasi-Isotropic Carbon-Fibre & Corum(2002) & $120^{\circ}$ & 3.36E-05 & $6.68 \mathrm{E}-06$ & 0.192 & 1hour & 270 \\
\hline
\end{tabular}

Therefore a total of 7 experimental cases of creep-rupture were used to test energy based failure criteria. The first two cases are E glass fiber/urethane matrix composites with two different reinforcements; randomly orientated chopped strands and continuous strand, swirl-mat fibers. The other cases are crossply and quasi-isotropic composites reinforced with continuous T300 carbon fibers in a urethane matrix. The reinforcement was in the form $\left[ \pm 45^{\circ}\right]_{3 S}$ crossply composite and $\left[0 \% / 90^{\circ} / \pm 45^{\circ}\right]_{S}$ quasi-isotropic 
composite. The results are plotted throughout Figs. 9-15. In all cases MWS and MR-W failure criteria predict similar lifetimes and R-W predict systemically higher lifetimes for each stress load. In most cases experimental data fall between R-W and MR-W failure criteria. The exception is for the crossply carbon fiber $\left[+45^{\circ} /-45^{\circ}\right]$ composite at $23^{\circ} \mathrm{C}$. In this case experimental data lifetime is higher, but close to $\mathrm{R}-\mathrm{W}$ predictions. In these cases, it appears that the energy-based failure criteria present a remarkable potential to extrapolate experimental creep-rupture data with a high degree of confidence.

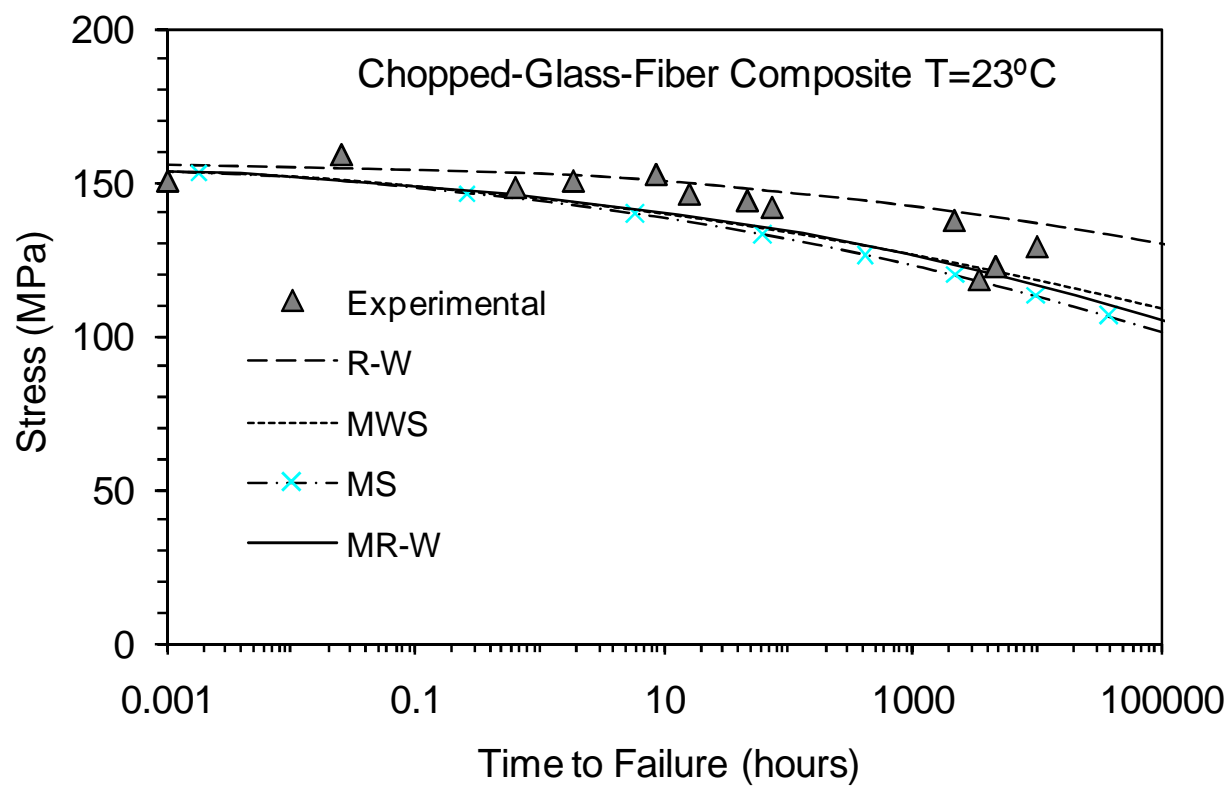

Figure 9: Experimental and calculated creep lifetime for Chopped-Glass-Fibre composite. 


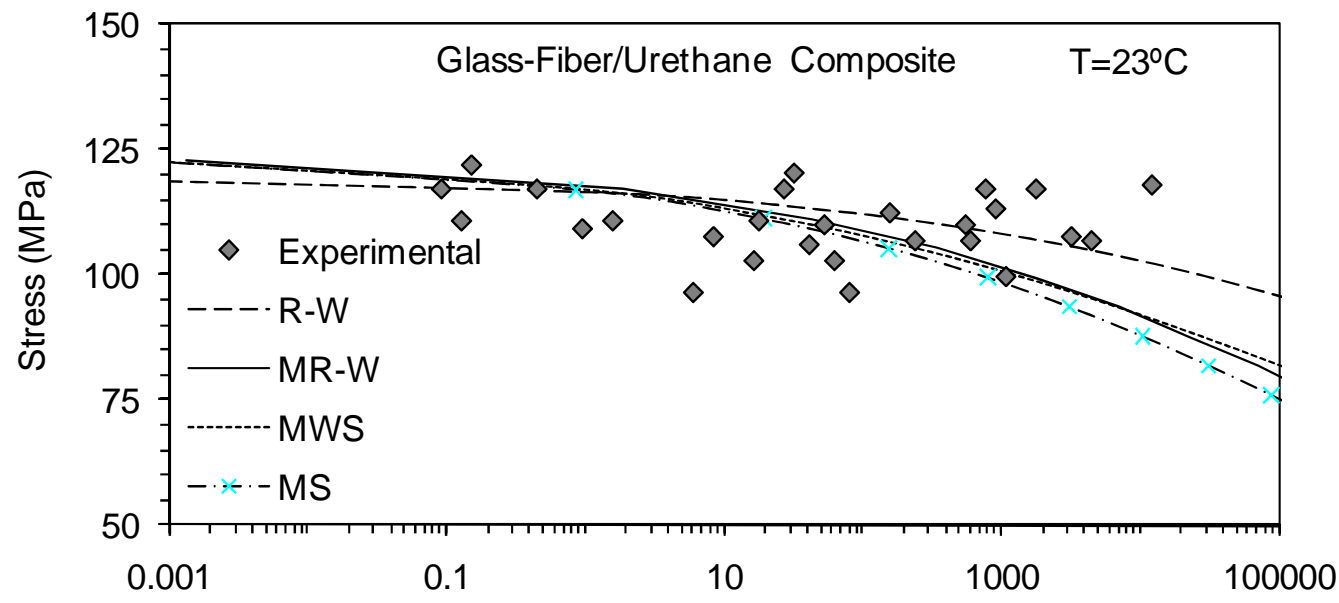

Time to Failure (hours)

Figure 10: Experimental and calculated creep lifetime for Glass-Fibre /Urethane composite at $23^{\circ} \mathrm{C}$.

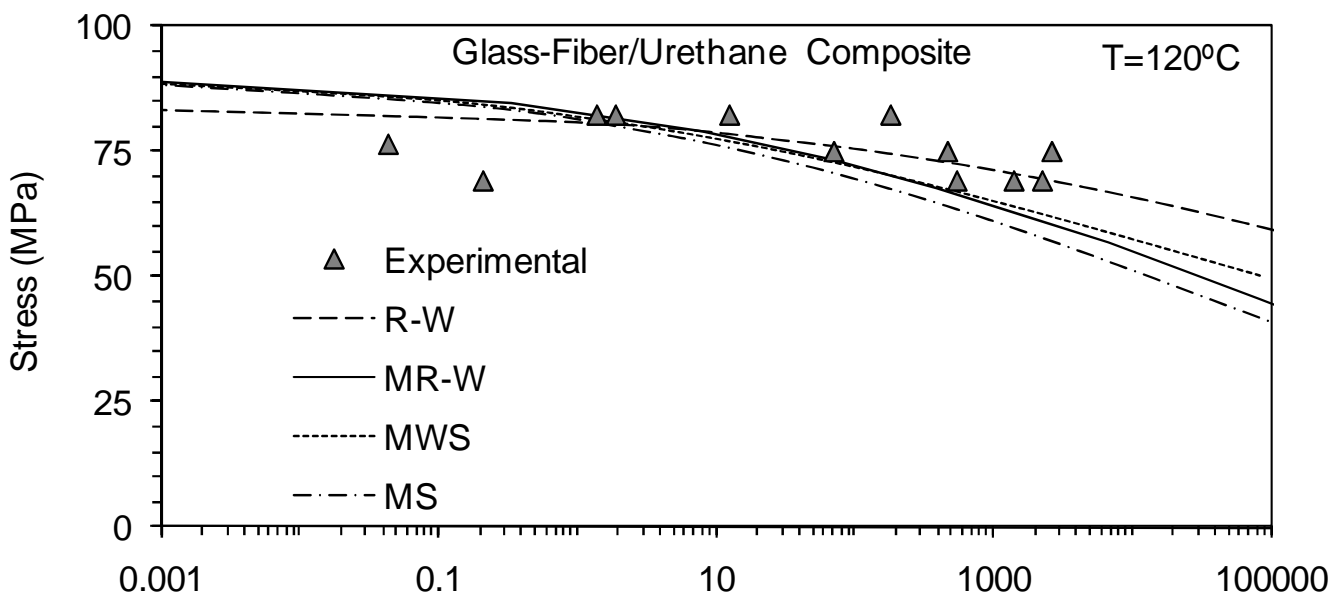

Time to Failure (hours)

Figure 11: Experimental and calculated creep lifetime for Glass-Fibre /Urethane composite at $120^{\circ} \mathrm{C}$. 


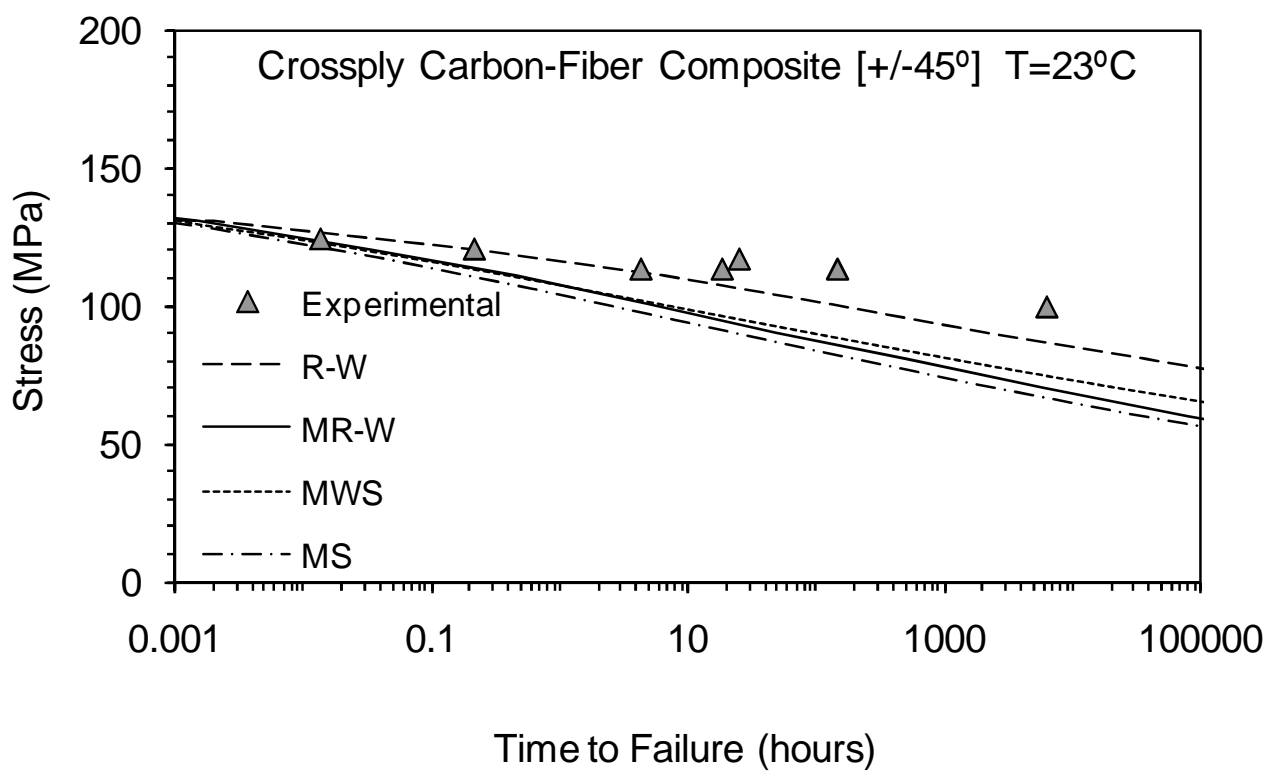

Figure 12: Experimental and calculated creep lifetime for Crossply Carbon-Fibre $45^{\circ} / 45^{\circ}$ at $23^{\circ} \mathrm{C}$.

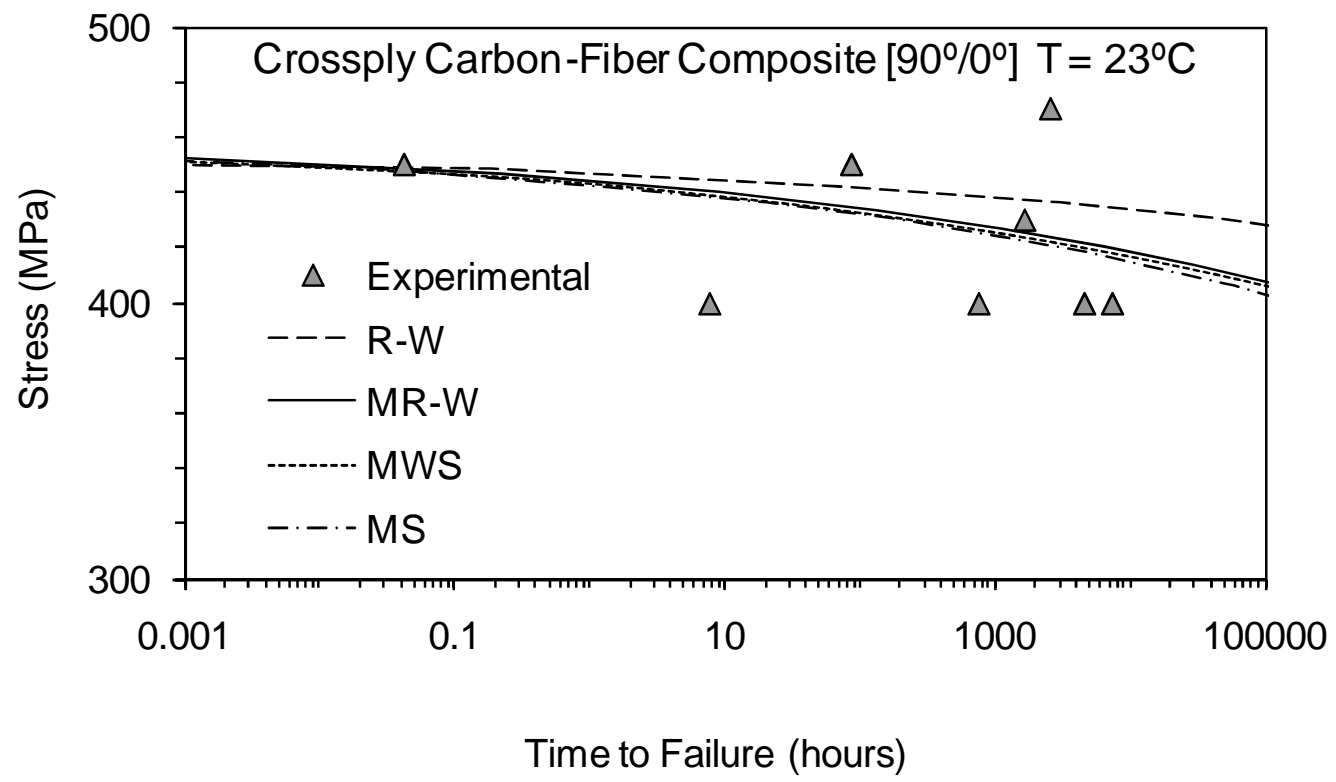

Figure 13: Experimental and calculated creep lifetime for Crossply Carbon-Fibre $90^{\circ} / 0^{\circ}$ composite at $23^{\circ} \mathrm{C}$. 


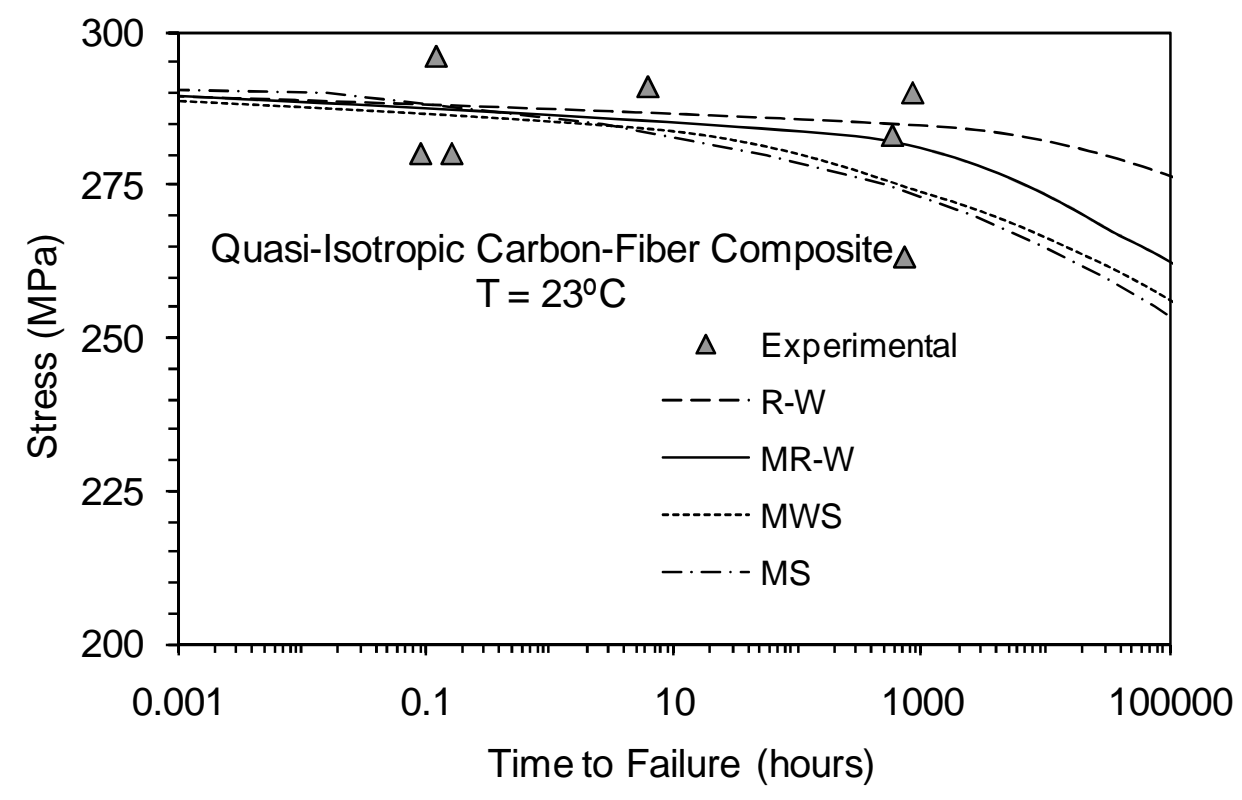

Figure 14: Experimental and calculated creep lifetime for Quasi-Isotropic Carbon-Fibre composite at $23^{\circ} \mathrm{C}$.

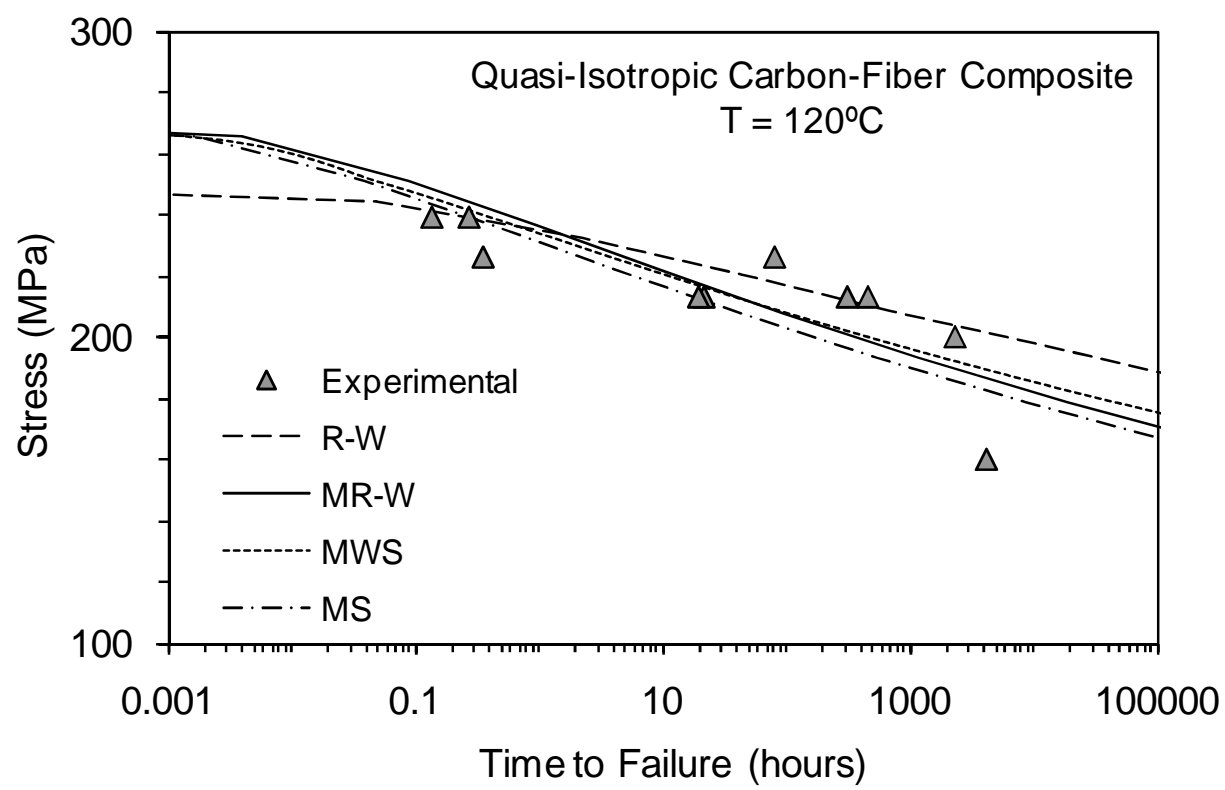

Figure 15: Experimental and calculated creep lifetime for Quasi-Isotropic Carbon-Fibre composite at $120^{\circ} \mathrm{C}$. 


\section{Time-Temperature Superposition Principle}

Creep strength for different composites is used to illustrate the potential applicability of the previous approaches in an extended time scale by using the Time-Temperature Superposition Principle (TTPS). One composite system is the CFRP laminates consisting of nine layers of plain woven cloth of carbon fibre and matrix vinylester resin. These CFRP laminates (T300/VE) were molded by the resin transfer molding (RTM) method and cured for $48 \mathrm{~h}$ at room temperature and for $2 \mathrm{~h}$ at $150^{\circ} \mathrm{C}$. The volume fraction of the fibre in the CFRP is approximately 52\% [21]. Another is a carbon fibre reforced polymer, UT500/135 which consists of twill-woven UT500 carbon fibre and 135 epoxy resin [56]. The last one is the T800S/3900-2B composite which consists of unidirectional T800 carbon fibre and 3900 epoxy resin with toughened interlayer [56].

The input data for the lifetime models, i.e., the viscoelastic properties and the strength under instantaneous conditions, are presented in Table 7.

As it can be observed the theoretical prediction are in good agreement with experimental results.

Table 7: Viscoelastic and rupture parameters of the composite materials.

\begin{tabular}{ccccccc}
\hline \multirow{2}{*}{ Material } & Ref. & \multicolumn{3}{c}{ Creep Compliance (1/MPa) } & \multicolumn{2}{c}{$\begin{array}{c}\text { Instantaneous Failure } \\
\text { Stress (MPa) }\end{array}$} \\
\cline { 3 - 7 } & & $D_{0}$ & $D_{1}$ & $n$ & $\tau_{0}$ & $\sigma_{R}$ \\
\hline T300/VE & Miyano (2005) & $3.60 \mathrm{E}-04$ & $1.69 \mathrm{E}-05$ & 0.209 & $1 \mathrm{~min}$ & 700 \\
T800S/3900-2B & Miyano (2006) & $1.85 \mathrm{E}-05$ & $6.33 \mathrm{E}-07$ & 0.119 & $1 \mathrm{~min}$ & 830 \\
UT500/135 & Miyano (2006) & $2.60 \mathrm{E}-05$ & $2.55 \mathrm{E}-08$ & 0.281 & $1 \mathrm{~min}$ & 500 \\
\hline
\end{tabular}


In many cases the Time-Temperature Superposition Principle (TTSP) applied to creep compliance $D(t ; T)$ holds valid for static and creep strength $\sigma_{R}\left(t_{f} ; T\right)$ with the same shift factors $a_{T}(T)$,

$D\left(t ; T_{0}\right)=D\left(\frac{t}{a_{T}\left(T_{1}\right)} ; T_{1}\right) \Rightarrow \sigma_{R}\left(t_{f} ; T_{0}\right)=\sigma_{R}\left(\frac{t_{f}}{a_{T}\left(T_{1}\right)} ; T_{1}\right)$,

where $T$ represents the temperature and $T_{0}$ the reference temperature. From this a reduced time to failure is defined as

$t_{f}^{\prime}=\frac{t_{f}}{a_{T}(T)}$

As an example the shift factors for the T300/VE composite were determined as [21],

$$
\ln \left(a_{T} ; T_{0}\right)=\frac{\Delta H}{G}\left(\frac{1}{T}-\frac{1}{T_{0}}\right),\left\{\begin{array}{l}
\Delta H=163 \mathrm{KJ} / \mathrm{mol}, T<90^{\circ} C \\
\Delta H=504 \mathrm{KJ} / \mathrm{mol}, T>90^{\circ} C
\end{array}\right\},
$$

where is $G$ the gas constant $8.314 \mathrm{E}-3 \mathrm{KJ} /(\mathrm{K} \mathrm{mol})$

Using the shift factors in the time dependent failure criteria applied for the T300/VE it was possible to predict the lifetime for each temperature with good agreement with experimental data, as depicted in Figure 16. 


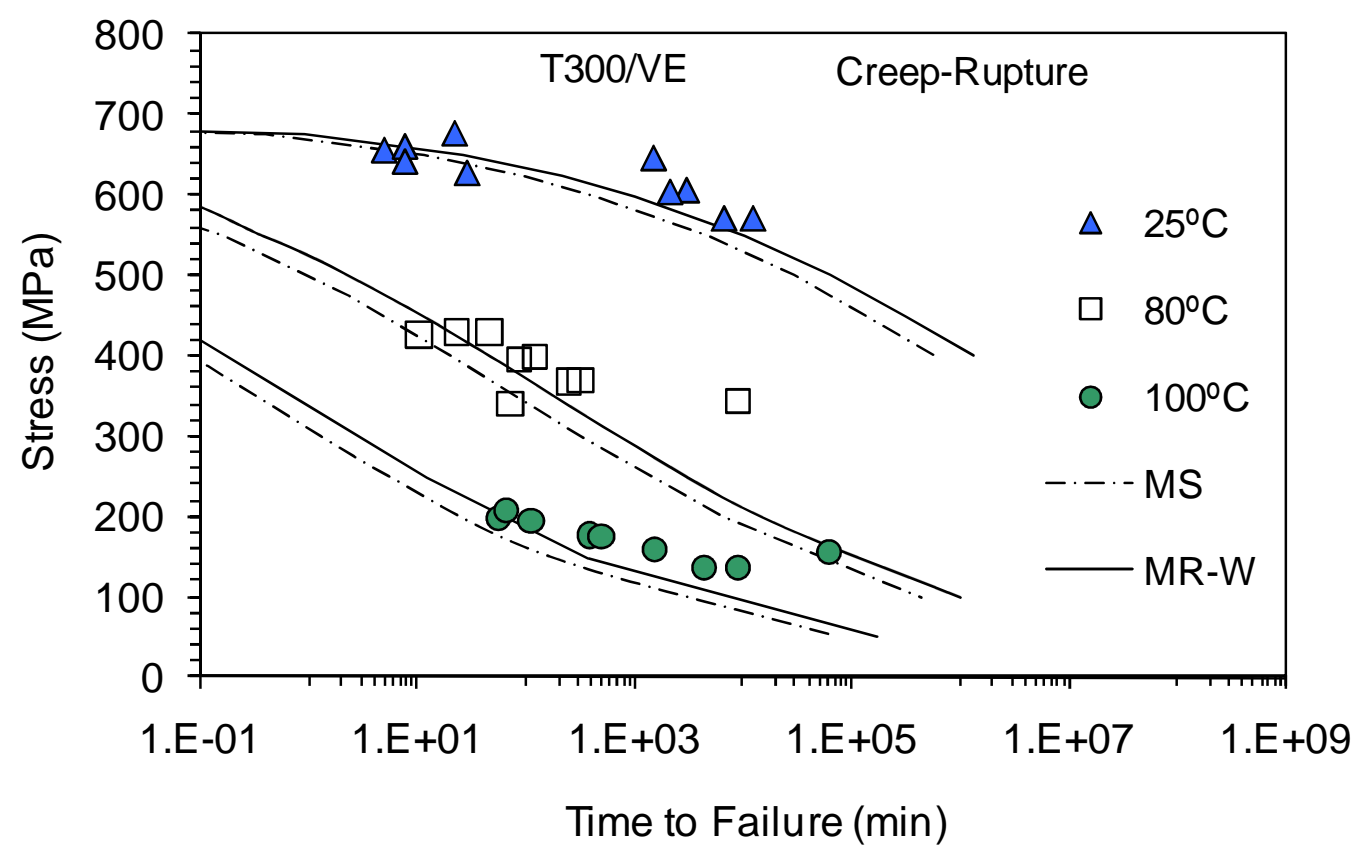

Figure 16: Experimental and calculated creep lifetime for T300/VE composite at different temperatures.

Consequently it become possible to predict the creep lifetime for an enlarged time scale, using the TTSP and the concept of reduce time. This can be observed in the next Figures (17-19). It can be concluded that the time dependent failure criteria is in good agreement with experimental data. In all cases the MS and MR-W lifetime predictions match quite well the experimental data. 


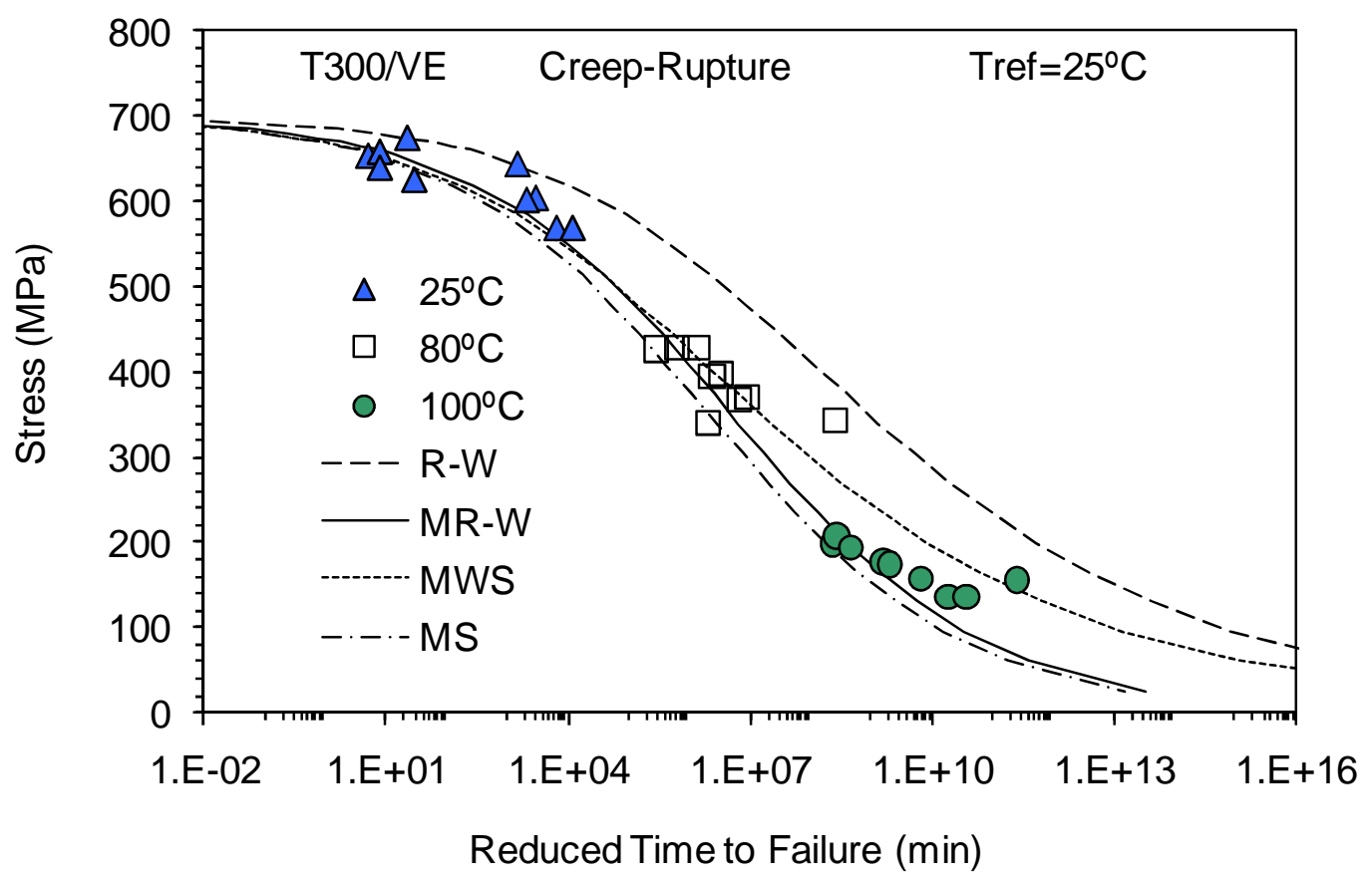

Figure 17: Experimental and calculated creep reduced lifetime for T300/VE composite.

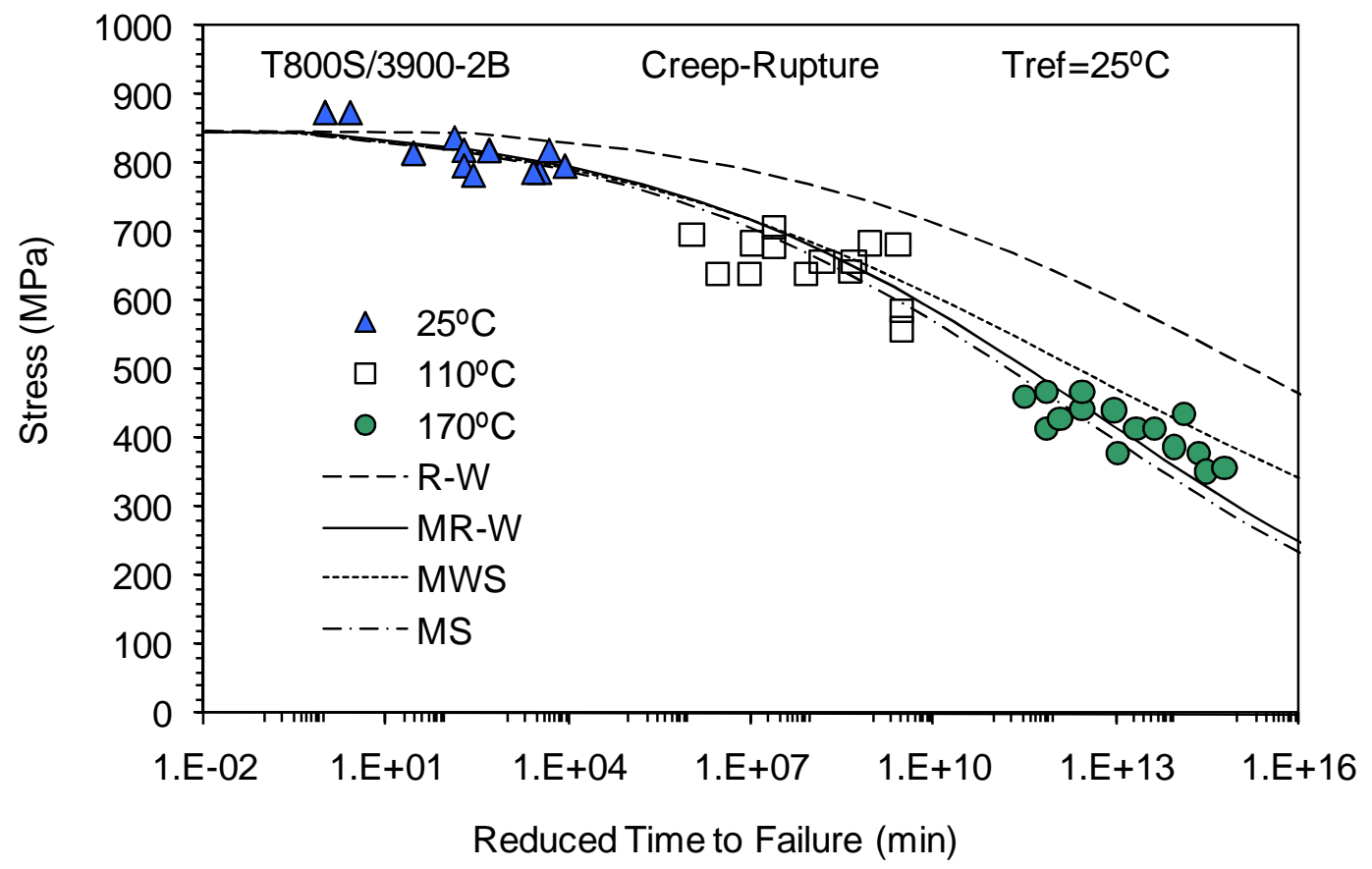

Figure 18: Experimental and calculated creep reduced lifetime for T800/3900-2B composite. 


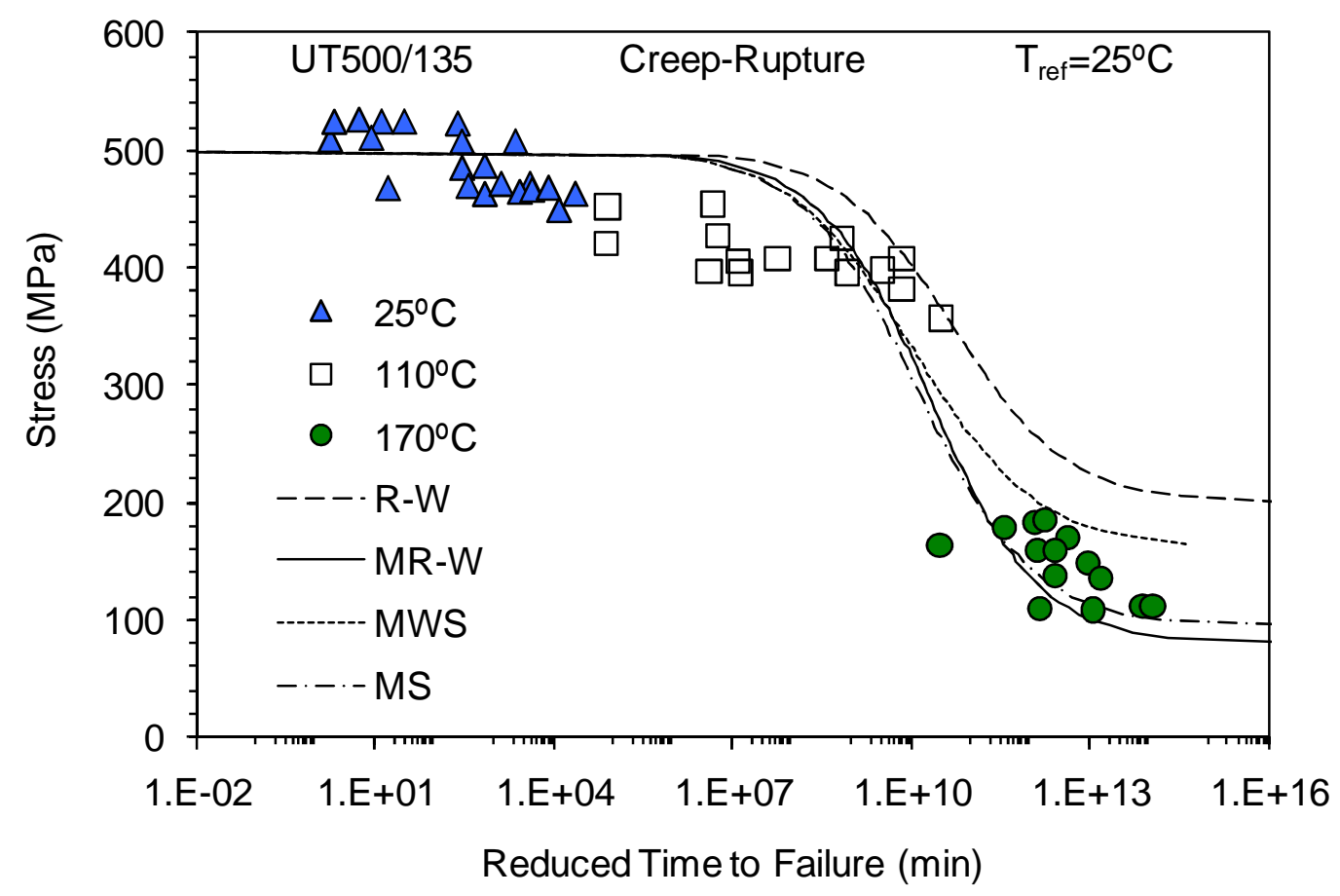

Figure 19: Experimental and calculated creep reduced lifetime for UT500/135 composite.

\section{THE CROCHET MODEL (TIME DEPENDENT YIELDING MODEL)}

A multi-axial yield/failure model for viscoelastic/plastic materials was developed by Naghdi and Murch [57] and later extended and refined by Crochet [58]. This approach was recently revised by Brinson [33]. In this theory, the total strain is assumed to be the sum of the viscoelastic and plastic strains. Stresses and strains are separated into elastic and viscoelastic deviatoric and dilatational components.

The yield function is given as

$f\left(\sigma_{i j}, \varepsilon_{i j}{ }^{p}, \chi_{i j}, \kappa_{i j}\right)=0$ and $\chi_{i j}=\chi_{i j}\left(\varepsilon_{i j}{ }^{V}-\varepsilon_{i j}{ }^{E}\right)$, 
Crochet gave specific form to the function $\chi_{\mathrm{ij}}$ such that

$\chi_{i j}=\sqrt{\left(\varepsilon_{i j}^{V}-\varepsilon_{i j}^{E}\right)\left(\varepsilon_{i j}^{V}-\varepsilon_{i j}^{E}\right)}$,

and defined a time dependent uniaxial yield function as (empirical equation)

$\sigma_{y}(t)=A+B e^{-C \chi}$

where $A, B$ and $C$ are material constants. No additional explanation for this empirical equation was given by Crochet[58]. Assuming a linear viscoelastic law given the power law, the creep strain, under $\sigma(t)=\sigma_{0}$, can be calculated as

$\varepsilon(t)=D_{0} \sigma(t)+D_{1}\left(\frac{t}{\tau_{0}}\right)^{n} \sigma_{0}$

The difference between viscoelastic and elastic strains in creep loading conditions becomes

$\left(\varepsilon_{11}{ }^{V}-\varepsilon_{11}{ }^{E}\right)^{2}=\left[D_{1}\left(\frac{t}{\tau_{0}}\right)^{n} \sigma_{0}\right]^{2}$

and the lateral strains become, upon assuming a constant Poisson's ratio $v$,

$\left(\varepsilon_{22}{ }^{V}-\varepsilon_{22}{ }^{E}\right)^{2}=\left(\varepsilon_{33}{ }^{V}-\varepsilon_{33}{ }^{E}\right)^{2}=v^{2}\left[D_{1}\left(\frac{t}{\tau_{0}}\right)^{n} \sigma_{0}\right]^{2}$,

The time factor, $\chi$, in Crochet's time-dependent yield criteria for uniaxial tension now becomes,

$\chi=\sqrt{1+2 v^{2}}\left[D_{1}\left(\frac{t}{\tau_{0}}\right)^{n} \sigma_{0}\right]$

Using the previous formulations an equation for the time to yield, $t_{c}$, for a linear viscoelastic material can be found 
$\frac{t_{c}}{\tau_{0}}=\left[\frac{1}{C \sigma_{f}} \frac{1}{D_{1} \sqrt{1+2 v^{2}}} \ln \left(\frac{B}{\sigma_{f}-A}\right)\right]^{1 / n}$,

where the symbol $\sigma_{f}$ is used, instead of $\sigma_{y}$, to indicate that the process may be used as well for creep rupture.

Since the relationship between yield (or failure) stress and $\chi$ is empirical, the suggested form given by Crochet can be questioned. For instance, the time dependent uniaxial yield (or failure) function can be given by a simple linear equation, i.e.,

$\sigma_{f}(t)=\alpha+\beta \chi$

where $\alpha$ and $\beta$ are material constants. Following the previous developments the lifetime expression becomes

$$
\frac{t_{f}}{\tau_{0}}=\left[\frac{1}{\beta D_{1} \sqrt{1+2 v^{2}}} \frac{\sigma_{f}-\alpha}{\sigma_{f}}\right]^{\frac{1}{n}},
$$

This expression remarkably resembles the lifetime formulations obtained for energy based time dependent failure criteria.

For uniaxial cases it is an interesting exercise to plot the evolution of creep failure stress versus the $\chi$ function. In this manner it becomes possible conclude about the best empirical approach to relate both parameters. The experimental data was previously given for the thermoplastics, polyamide 66 (Nylon 66 A100) unfilled, polyamide 66 filled with $30 \%$ of glass fibre (Nylon 66 A190) [48] at room temperature and polycarbonate (PC Lexan 141) [49] at room temperature. The evolution of creep failure stress with $\chi$ function was plotted and linear and exponential equations were fitted considering just the initial $24 \mathrm{~h}$ experimental data. The results are depicted in Figures (20-25). 


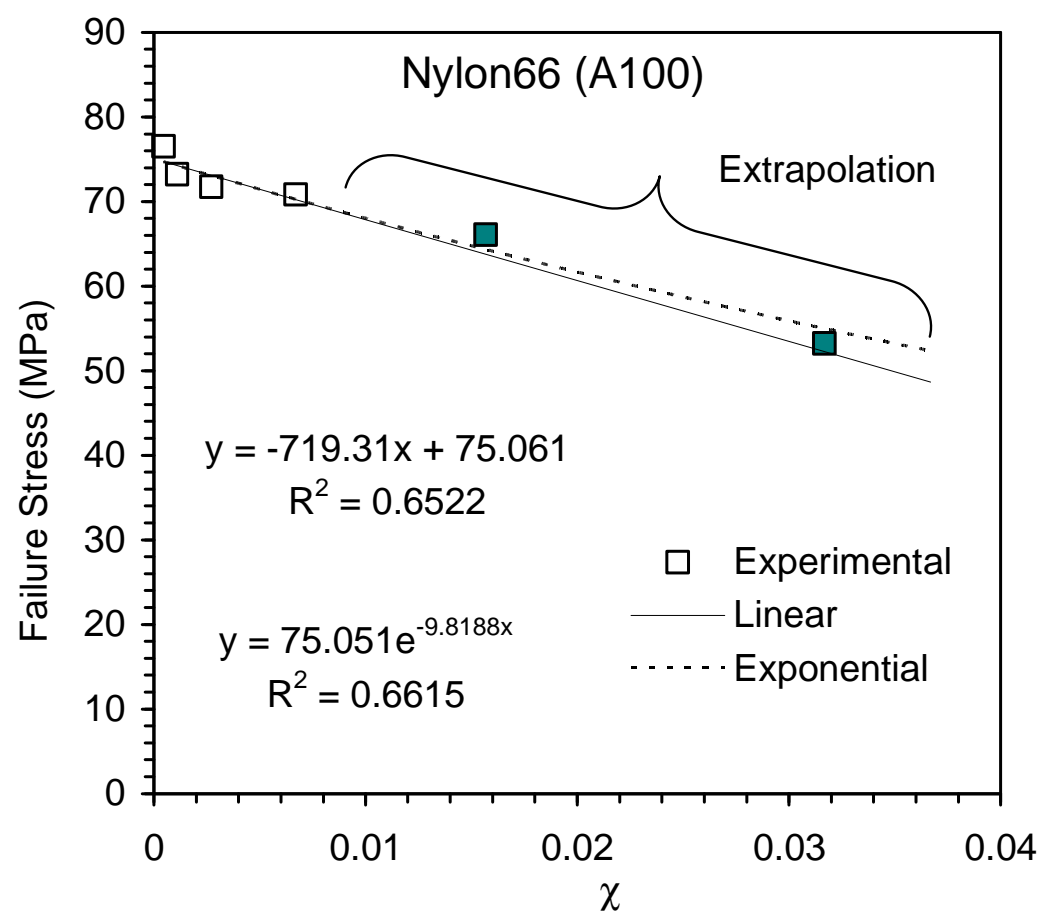

Figure 20: Experimental and fitted curves for the creep failure stress as function of $\chi$ function for Nylon66 (A100).

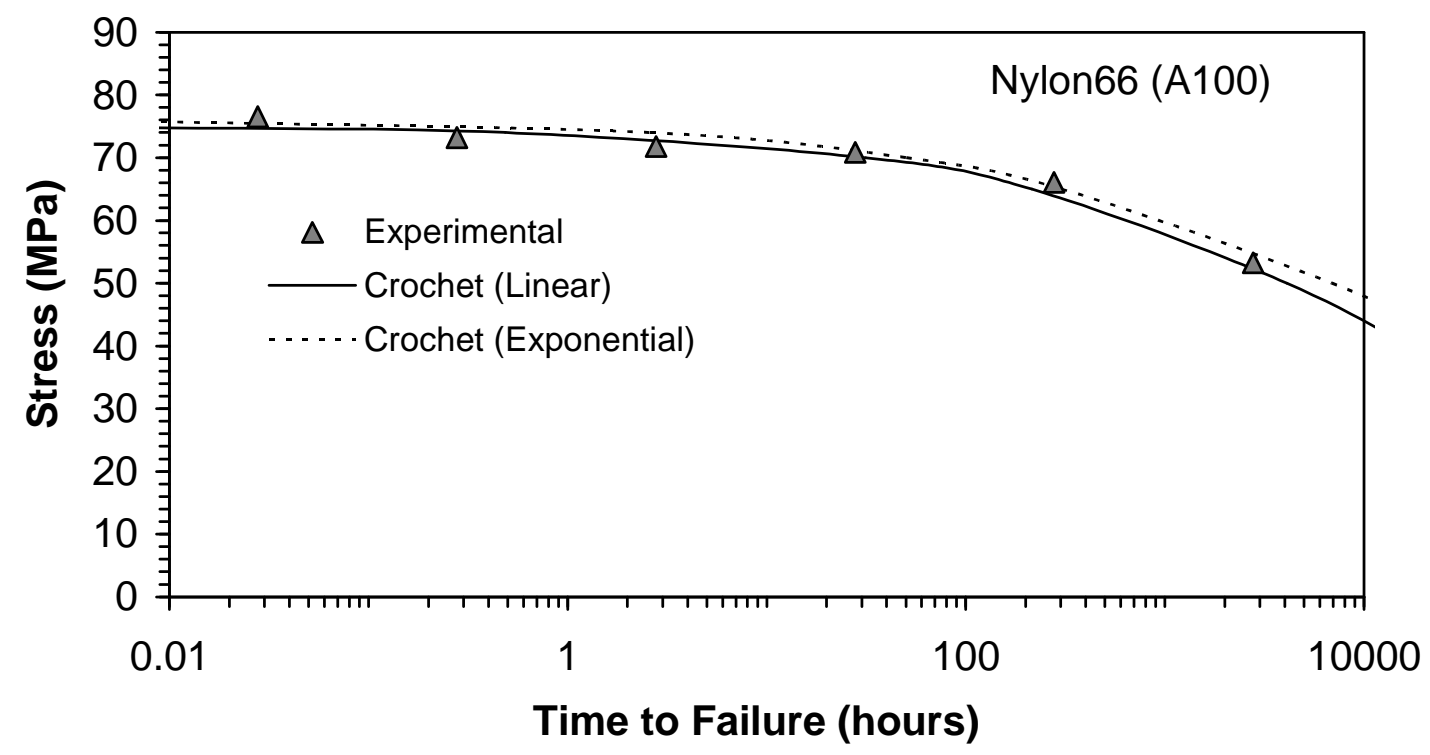

Figure 21: Experimental and predicted creep lifetime using Chrochet model for Nylon66 (A100). 


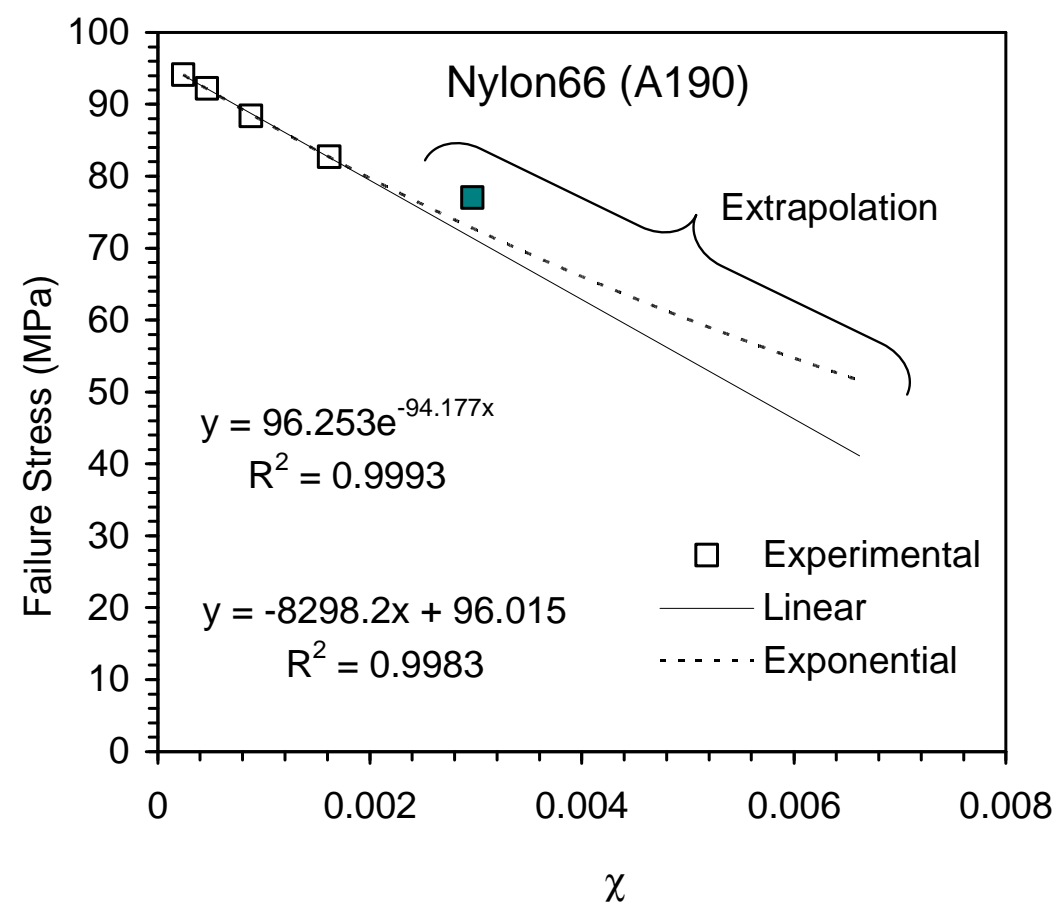

Figure 22: Experimental and fitted curves for the creep failure stress as function of $\chi$ function for Nylon66 (A190).

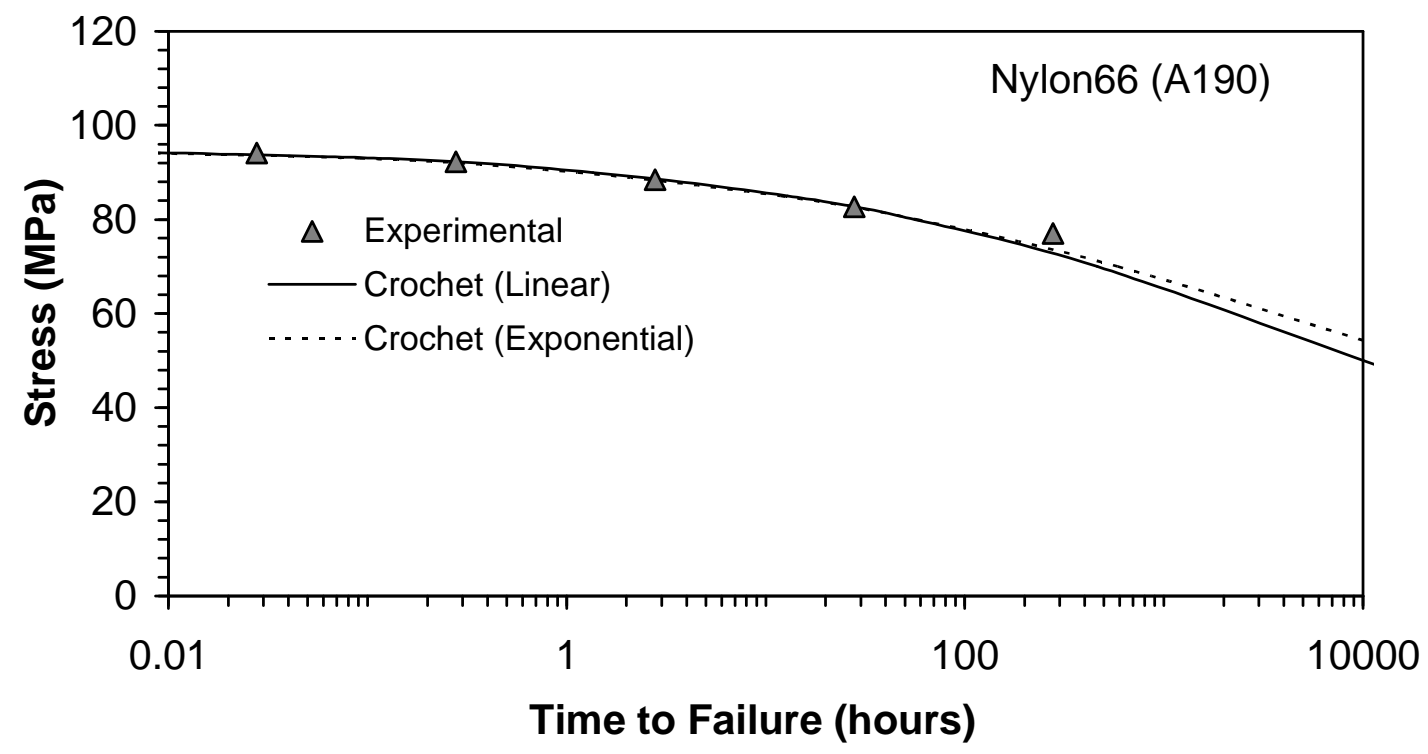

Figure 23: Experimental and predicted creep lifetime using Chrochet model for Nylon66 (A190). 


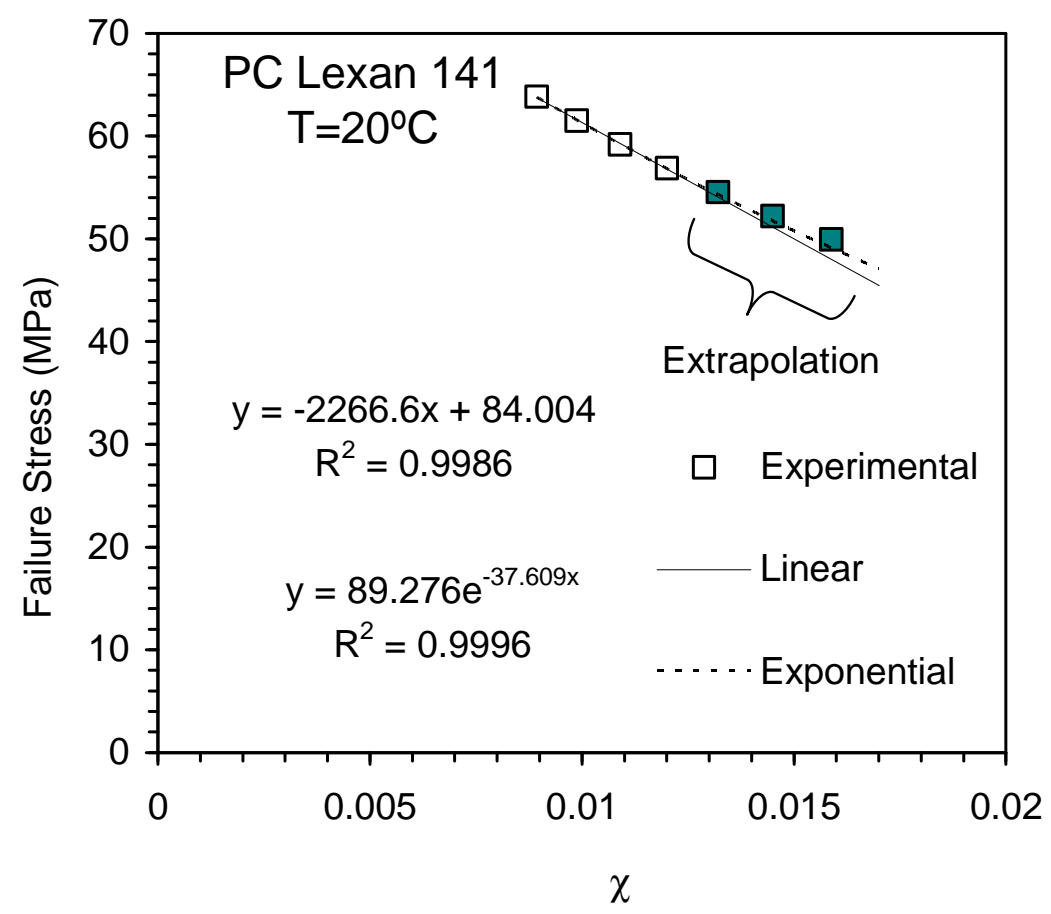

Figure 24: Experimental and fitted curves for the creep failure stress as function of $\chi$ function for PC Lexan 141.

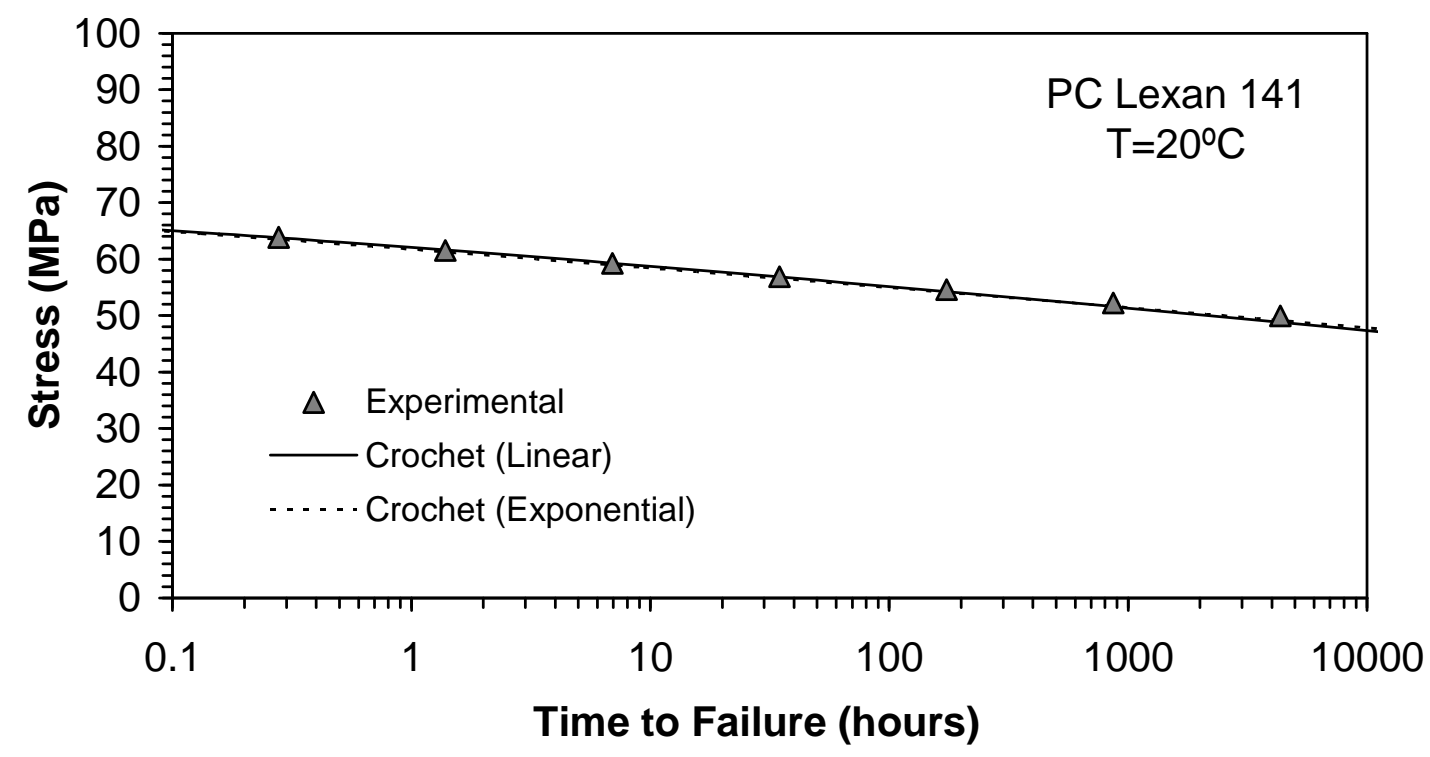

Figure 25: Experimental and predicted creep lifetime using Chrochet model for PC Lexan 141. 
These results show that the simple linear relationship between the creep stress and the function $\chi$ could be sufficient to fit experimental data. Furthermore, for the present cases, the extrapolation for the long-term gives lifetime predictions in good agreement with experimental data.

Expanding this exercise to larger time scales, obtained by applying the TTSP, the experimental data published for the CFRP laminates (T300/VE) [21] and for the T800S/3900-2B laminate [56] was used. Like before, the evolution of creep failure stress with $\chi$ function was plotted and linear equations were fitted, in this case, using just the lower temperature experimental data. The tresults are depicted in the following Figures (26-29).

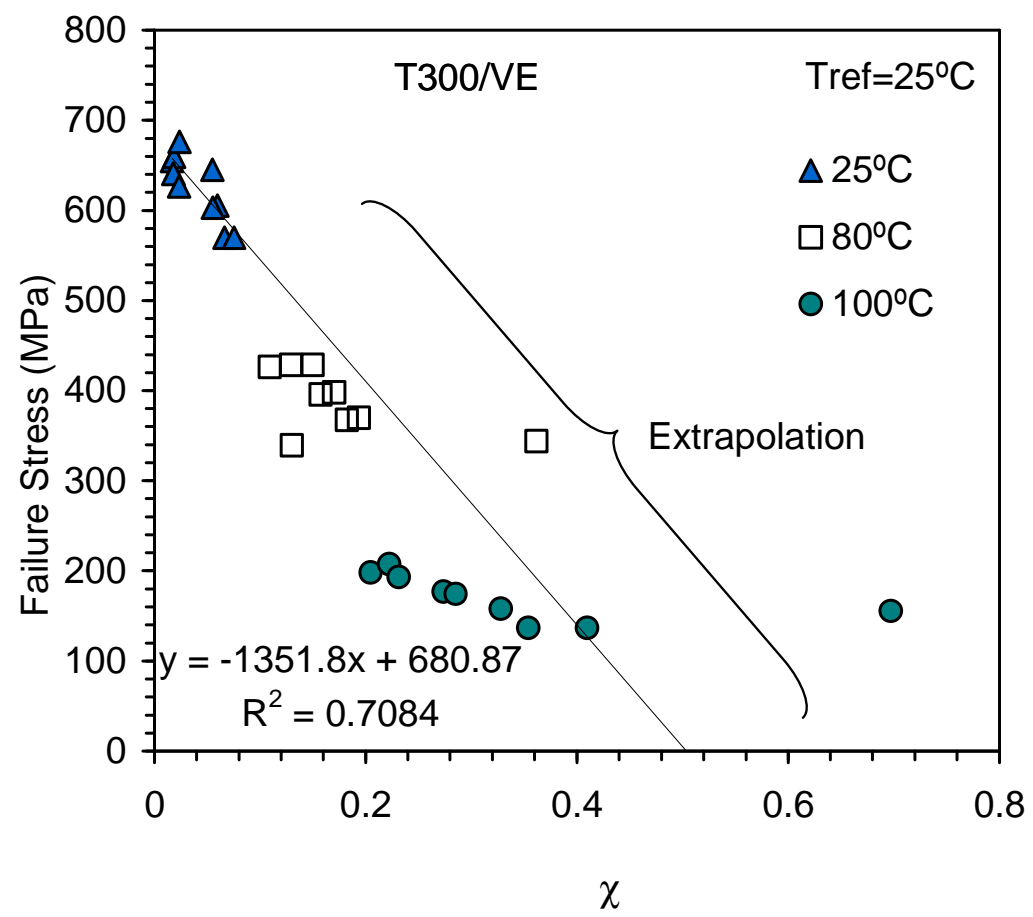

Figure 26: Experimental and fitted curves for the creep failure stress as function of $\chi$ function for the composite T300/VE. 


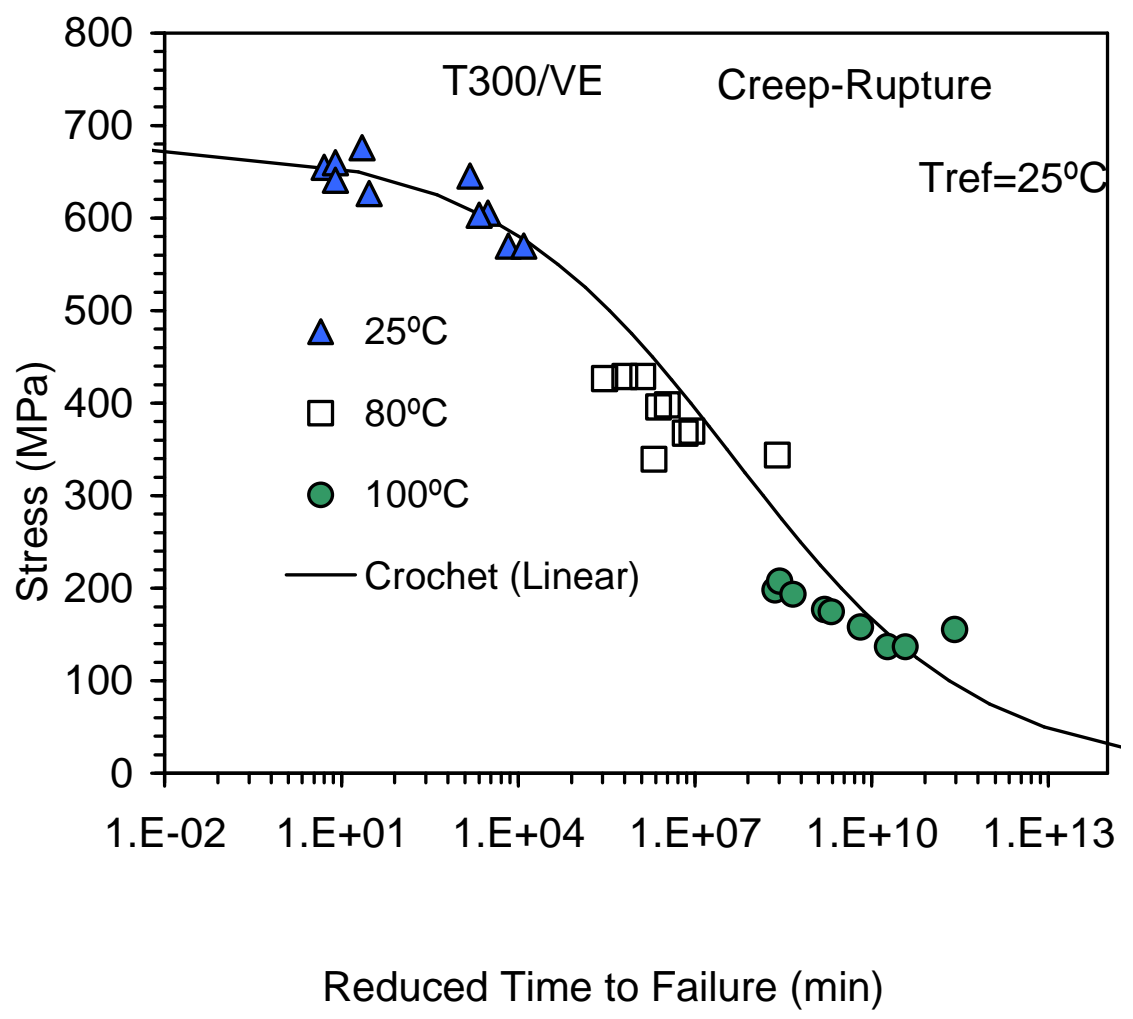

Figure 27: Experimental and predicted creep lifetime using Chrochet model for the composite T300/VE. 


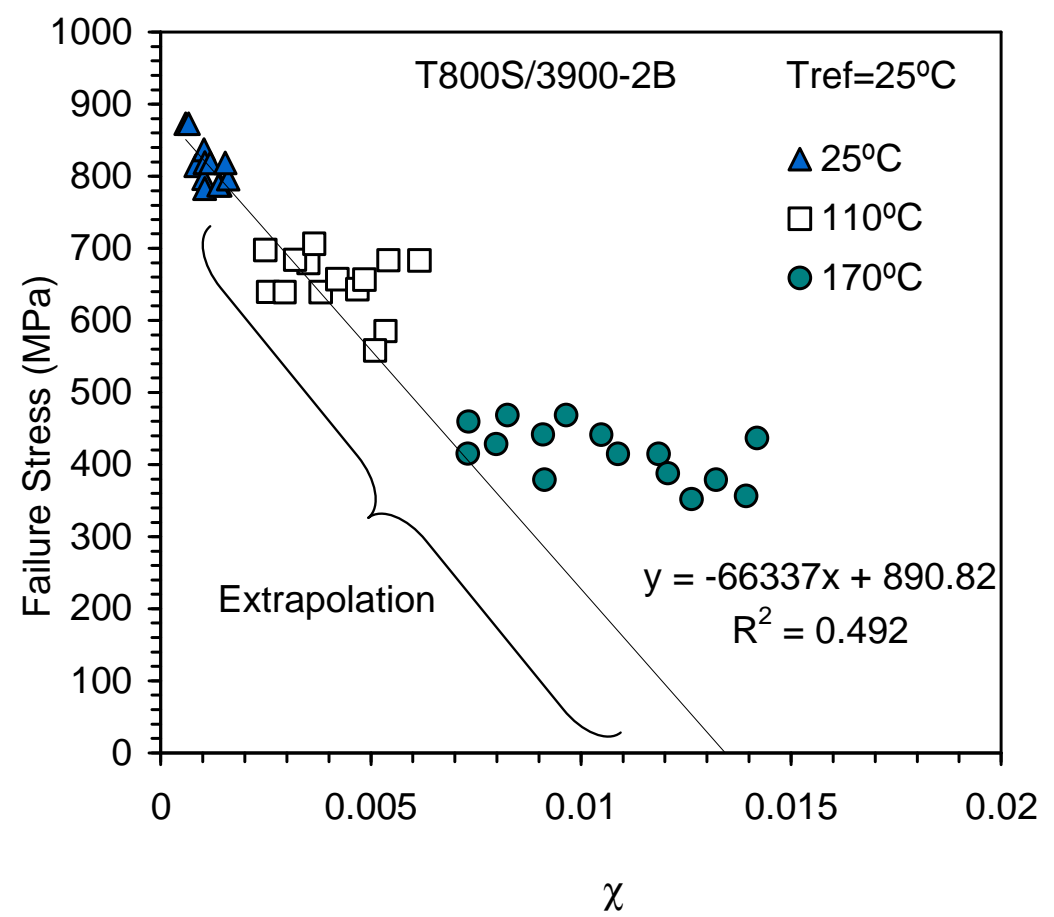

Figure 28: Experimental and fitted curves for the creep failure stress as function of $\chi$ function for the composite T800S/3900-2B. 


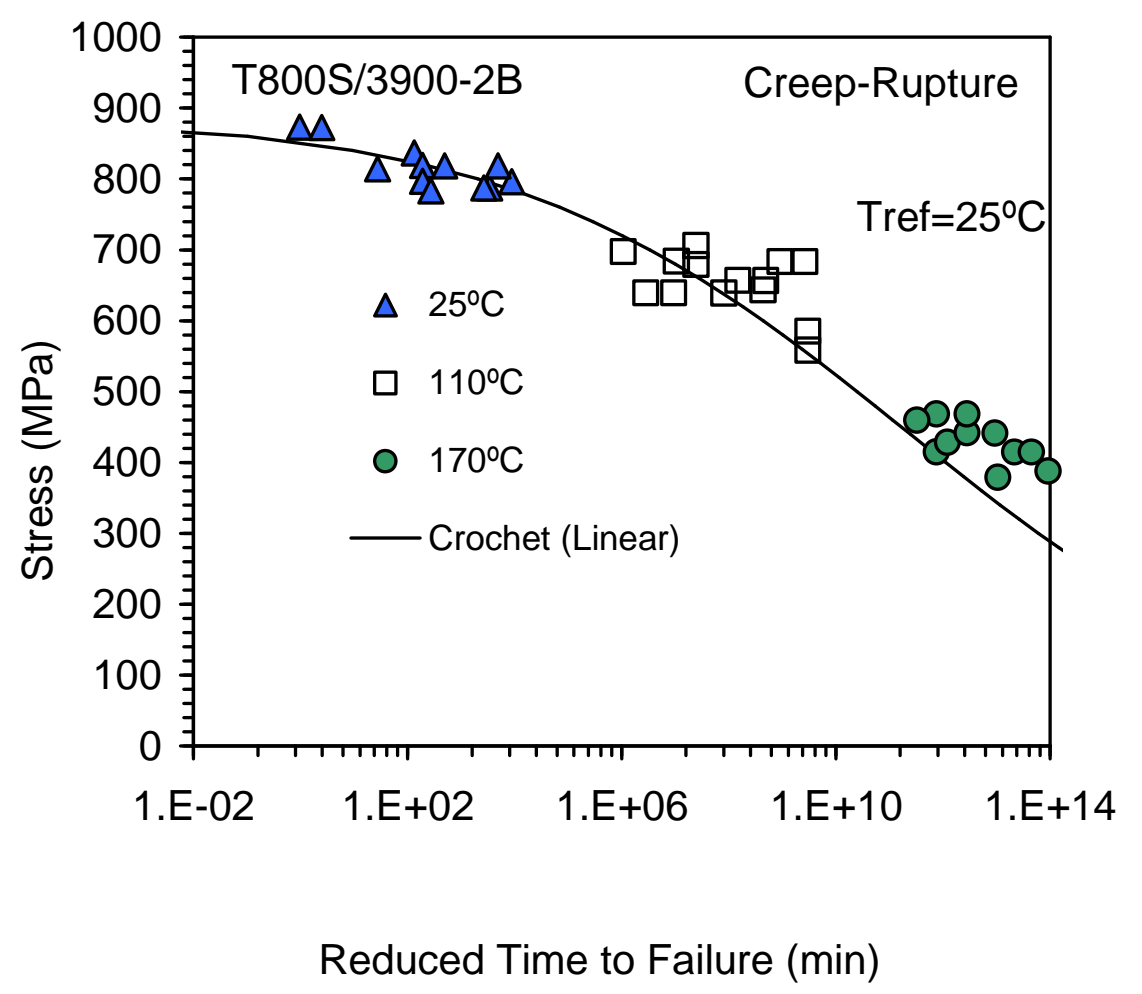

Figure 29: Experimental predicted creep lifetime using Chrochet model for the composite T800S/3900-2B.

Again these results show that the simple linear relationship between the creep stress and the function $\chi$ is sufficient to obtain good results. However the experimental data reveals that this relationship, in reality, appears to be of exponential type.

Nevertheless for the present cases the model extrapolation for the long-term, based on limited data, gives lifetime predictions in good agreement with experimental data.

\section{KINETIC RATE THEORY}


The rate theory of fracture is based on a molecular approach, i.e. on the kinetics of molecular flow and bond rupture of the polymer chains. Based on these approaches Zhurkov [59] presented on the first models to predict materials lifetime $t_{f}$ (except for very small stresses) in terms of a constant stress level $\sigma$,

$t_{f}=t_{0} \exp \left[\left(U_{0}-\gamma \sigma\right) / k T\right]$

where $t_{0}$ is a constant on the order of the molecular oscillation period of $10^{-13} \mathrm{~s}, k$ is the Boltzmann constant, $T$ is the absolute temperature, $U_{0}$ is a constant for each material regardless its structure and treatment and $\gamma$ depends on the previous treatments of the material and varies over a wide range for different materials. Griffith et al. [12] applied a modified version of Zurkov equation,

$t_{f}=t_{0} \exp \left(\frac{U_{0}}{k T}-\gamma \sigma\right)$

known as the modified rate equation, to predict the time to rupture of continuous fiberreinforced plastics with a reasonable success.

\section{FRACTURE MECHANICS EXTENDED TO VISCOELASTIC MATERIALS}

The fracture mechanics analysis was extended to viscoelastic media to predict the timedependent growth of flaws or cracks. Several authors developed extensive work on this area [60], [61], [41], [40], [62], [63]). Schapery [62], [63] developed a theory of crack growth which was used to predict the crack speed and lifetime for an elastomer under uniaxial and biaxial stress states Schapery [40]. For a centrally cracked viscoelastic 
plate with a creep compliance given by Equation (1) under constant load, Schapery [40] deduced, after some simplifications, a simple relation between stress and failure time,

$\left(\frac{t_{f}}{\tau_{0}}\right)=\left(B \sigma_{0}\right)^{-2(1+1 / n)}$,

where $n$ is the exponent of the creep compliance power law and $B$ a parameter which depends on the geometry and properties of the material. Leon and Weitsman [64] and Corum et al. [51] used this approach where $B$ was considered an experimental constant, to fit creep-rupture data with considerable success. Recently Christensen [65] developed a kinetic crack formulation to predict the creep rupture lifetime for polymers. The lifetime was found from the time needed for an initial crack to grow to sufficiently large size as to cause instantaneous further propagation. The method assumed quasi-static conditions and only applies to the central crack problem. The polymeric material was taken to be in the glassy elastic state, as would be normal in most applications. For general stress, $\sigma(t)$ we have,

$$
1-\left(\sigma(t) / \sigma_{R}\right)^{1 / m}=\int_{0}^{t_{f} /\left(\alpha \tau_{0}\right)}\left(\sigma(\tau) / \sigma_{R}\right)^{1 / m+1} d \tau,
$$

where $\gamma=\sigma_{0}{ }^{2} / \sigma_{R}{ }^{2}, m$ is the exponent of the power law relaxation function and $\alpha$ is a parameter governed by the geometry and viscoelastic properties. For constant stress, $\sigma=\sigma_{0}$, the lifetime is given as,

$$
\left(\frac{t_{f}}{\tau_{0}}\right)=\frac{\alpha}{\sqrt{\gamma}}\left(\frac{1}{\sqrt{\gamma}^{1 / m}}-1\right) .
$$




\section{CONTINUUM DAMAGE MECHANICS}

A classical approach to consider the degradation of mechanical properties is provided by the method of continuum damage mechanics (CDM). Following the original ideas of Kachanov [66], the net stress, defined as the remaining load bearing cross section of the material is given [67] by,

$\tilde{\sigma}=\frac{\sigma}{1-\omega}$,

where $0 \leq \omega \leq 1$ is the damage variable. At rupture no load bearing area remains and the net stress tends to infinity when $\omega \rightarrow 1$.

Kachanov [66] assumes the following damage growth law

$\dot{\omega}(t)=C\left(\frac{\sigma(t)}{1-\omega(t)}\right)^{v}$,

where $C$ and $v$ are material constants. This equation leads to a separable differential equation for $\omega(t)$, assuming $\omega(0)=0$

$(1-\omega(t))^{v} \dot{\omega}(t)=C \sigma^{v}(t) \Rightarrow 1-(1-\omega(t))^{1+v}=C(1+v) \int_{0}^{t} \sigma^{v}(\tau) d \tau$

The damage growth law is given as,

$\omega(t)=1-\left[1-C(1+v) \int_{0}^{t} \sigma^{v}(\tau) d \tau\right]^{\frac{1}{1+v}}$.

Assuming failure when $\omega=1$ then the following expression is obtained

$C(1+v) \int_{0}^{t} \sigma^{v}(\tau) d \tau=1$

From the previous relationship, the time to failure for creep is readily obtained assuming $\sigma(t)=\sigma_{0}$, 
$t_{c}=\frac{1}{C(1+v) \sigma_{0}^{v}}$.

Clearly this result is equivalent to the obtained previously by using the Schapery theory [40]. Therefore the creep lifetime expressions obtained for both theoretical approaches are directly comparable and are, in fact, equivalent, i.e.

$$
\left\{\begin{array} { r l } 
{ \frac { 1 } { C ( 1 + v ) } } & { = \frac { 1 } { \beta ^ { 2 ( 1 + 1 / n ) } } } \\
{ v } & { = 2 ( 1 + 1 / n ) }
\end{array} \Leftrightarrow \left\{\begin{array}{l}
\beta=[C(1+v)]^{\frac{1}{2(1+1 / n)}}, \\
n=\frac{2}{v-2}
\end{array},\right.\right.
$$

even thought the parameters have distinct physical interpretations.

\section{DAMAGE ACCUMULATION MODELS FOR STATIC (CREEP) AND DYNAMIC FATIGUE}

The damage evolution depends strongly on different factors acting simultaneously, i.e. temperature, moisture, stress, viscoelasticity, viscoplasticity, etc. By their turn these factors are time-dependent. In practice its influence on long-term failure is measured independently i.e. under constant conditions. Afterwards it is necessary a methodology to evaluate its combined effects. However this is this out of the scope of this chapter. One crucial question remaining to be solved completely is how to predict damage accumulation, or the remaining strength, after a fatigue or creep cycle at multiple stress levels, based on the fatigue and creep master curves. Miner's Rule [68] is an example of a simply way to account damage accumulation due to different fatigue cycles. This 
damage fraction rule is also designated by Linear Cumulative Damage law (LCD). For the fatigue it states that failure occurs when the following condition is verified

$\sum_{i}^{N} \frac{\Delta n_{i}\left(\sigma_{i}\right)}{n_{f}\left(\sigma_{i}\right)}=1$,

where $n_{f}$ is the number of cycles to failure at stress level $\sigma_{i}$ and $\Delta n_{i}$ is the number of cycles applied at each stress level $\sigma_{i}$ of the fatigue cycle. Hence equation (66) provides a failure criterion for fatigue. The corresponding form for creep conditions is given by

$\sum_{i}^{N} \frac{\Delta t_{i}\left(\sigma_{i}\right)}{t_{c}\left(\sigma_{i}\right)}=1$

where $t_{c}$ is the creep rupture lifetime at stress level $\sigma_{i}$ and $\Delta t_{i}$ is time applied at each stress level $\sigma_{i}$. Once more equation (67) specifies a criterion for lifetime at multiple stress levels. Latter Bowman and Barker [69] suggest a combination of both damage fraction rules to analyse experimental data, for thermoplastics tested until failure under a trapezoidal loading profile, which combined fatigue with creep. Although the Miner's rule can predict accurately failure of fibre -reinforced polymers under certain combined stress levels, it proved to be inappropriate in many other cases. However due to its simplicity, nowadays is still used by designers.

More sophisticated models, concerning fatigue of fibre -reinforced polymers, appeared in recent years [70], [71], [72], [73], [74] among others. These approaches are either empirical or semi-empirical. Yet these models aim to capture the inherent nonlinearity of damage accumulation, allowing predicting the fatigue behavior using a well-defined minimum number of tests. 
The conditions of applicability of Miner's rule were discussed by Christensen [75]. It provided a theoretical validation of the use of LCD law when relating creep failure conditions to constant stress (or strain) rate failure conditions. For that purpose Christensen [75] developed a very simple kinetic crack growth theory following the Schapery [40] formalism and based on a generalization to viscoelastic material of the Griffith result for elastic material. Guedes [39], [76] extended this validation by using other existing theoretical frameworks.

A cumulative damage theory developed to address various applied problems in which time, temperature, and cyclic loading are given explicitly, was developed by Reifsnider et al. [77], [78], [79].

The basic form of the strength evolution equation calculates the remaining strength $F_{r}$

$$
F_{r}=1-\int_{0}^{z}\left(1-F_{a}\left(\frac{\sigma(\tau)}{X(\tau)}\right)\right) j \tau^{j-1} d \tau,
$$

where $z=t / \tau, t$ is the time variable, $\tau$ is a characteristic time associated with the process, $F_{a}$ is the normalized failure function that applies to a specific controlling failure mode and $j$ is a material parameter. This material parameter influences the damage progression; if $j<1$ the rate of degradation is greatest at beginning but if $j>1$ the rate of degradation increase as function of time while if $j=1$ there is no explicit time dependence in the rate of degradation. The failure criterion is given by $F_{r}=F_{a}$.

The Strength Evolution Integral (SEI) has not been developed from the first-principles but based on few postulates combined with a kinetic theory of solids. Despite this shortcoming, SEI has been used successfully for almost 20 years, by Reifsnider et al. 
[77], [78], [79], to solve various applied problems in which time, temperature, and cyclic loading were explicit influences.

\section{CONCLUSIONS}

Several time-dependent failure criteria applied to polymers and polymer-based matrix composites were present and illustrated using experimental data of two different composites. All criteria, excluding the energy-based failure criteria and the MS criterion, must have some or all the parameters obtained by curve-fitting the experimental lifetime data. This happens because the background theories lead to relative simple expressions recurring to empirical laws and simplifications, which ultimately enclose several variables related to the basic properties, with physical meaning, into few parameters. Consequently it becomes impossible to determine these parameters based on the basic properties, i.e. geometry, elastic and viscoelastic parameters and instantaneous strength. However, in this form, these lifetime expressions possess a more general character than it was initially devised.

One important characteristic of these criteria it is their forecast lifetime capability, based on short-time experimental data. In that respect all the present approaches appear to possess this capability. This review also shows the remarkable ability of energy-based failure and MS criteria to forecast lifetime based on viscoelastic parameters and instantaneous strength. 


\section{REFERENCES}

[1] Karbhari VM, Chin JW, Hunston D, et al. Durability gap analysis for fibre reinforced polymer composites in civil infrastructure. Journal of Composites for Construction (3): 238-247 2003

[2] Guedes RM, Sá A, Faria H. On the Prediction of Long-Term Creep-Failure of GRP Pipes in Aqueous Environment. Polymer Composites 2008 (in press).

[3] Gotham, K.V. 1972. Long-term strength of thermoplastics: the ductile-brittle transition in static fatigue. Plastics \& Polymers 40:59-64.

[4] Reifsnider, K., Stinchcomb, W. \& Osiroff, R. 1992. Modeling of Creep Rupture Mechanisms in Composite Material Systems. ASME AD 27:51-58

[5] Brüller, O.S. 1973. The Energy Balance of a Viscoelastic Material. International Journal of Polymeric Materials 2:137-148.

[6] Brüller, O.S. 1978. On the Damage Energy of Polymers. Polymer Engineering and Science 18(1):42-44.

[7] Bruller, O.S. 1981. Energy-Related Failure of Thermoplastics. Polymer Engineering Science 21(3):145-150.

[8] Reiner M., Weissenberg K. A thermodynamic theory of the strength of the materials. Rheol Leaflet 1939;10:12-20.

[9] Theo, S.H. 1990. Computational aspects in creep rupture modelling of polypropylene using an energy failure criterion in conjunction with a mechanical model. Polymer 31:2260-2266.

[10] Teoh, S.H., Cherry, B.W. \& Kaush, H.H.1992. Creep rupture modelling of polymers. International Journal of Damage Mechanics 1(2):245-256.

[11] Boey, F.Y.C. \& Teoh, S.H. 1990. Bending Creep Rupture Analysis using a Nonlinear Criterion Approach. Materials Science and Engineering A123:13-19.

[12] Griffith, W.I. Morris, D.H. \& Brinson, H.F. 1980. The accelerated characterization of viscoelastic composite materials. Virginia Polytechnic Institute Report VPI-E-80-15: Blacks-burg, VA.

[13] Dillard, D.A: 1981. Creep and Creep Rupture of Laminated Graphite/Epoxy Composites. PhD Thesis: Virginia Polytechnic Institute and State University.

[14] Dillard, D.A. 1991. Viscoelastic Behavior of Laminated Composite Materials. In K.L. Reifsneider (ed.), Fatigue of Composite Materials, Composite Materials Series 4: 339-384. Elsevier: Amsterdam. 
[15] Hiel, C., 1983a. The Nonlinear Viscoelastic Response of Resin Matrix Composites. PhD Thesis: Free University of Brussels (V.U.B.).

[16] Raghavan, J. \& Meshii M. 1997. Creep Rupture of Polymer Composites. Composite Science and Technology 57:375-388.

[17] Raghavan, J. \& Meshii, M. 1996. Time-dependent damage in carbon fibrereinforced polymer composites. Composites - Part A 27(12):1223-1227.

[18] Miyano Y, McMurray MK, Enyama J, Nakada M, Loading rate and temperature dependence on flexural fatigue behavior of a satin woven CFRP laminate, Journal of Composite Materials 28(13) (1994): 1250-1260.

[19] Miyano Y, Nakada M, McMurray MK, Muki R, Prediction of flexural fatigue strength of CRFP composites under arbitrary frequency, stress ratio and temperature, Journal of Composite Materials 31(6) (1997): 619-638.

[20] Miyano Y, Nakada M, Kudoh H, Muki R, Prediction of tensile fatigue life for unidirectional CFRP, Journal of Composite Materials 34(7) (2000): 538-550.

[21] Miyano Y, Nakada M, Sekine N. Accelerated testing for long-term durability of FRP laminates for marine use. Journal of Composite Materials 39 (1): 5-20 2005.

[22] Alava MJ, Nukalaz PKVV, Zapperi S. Statistical models of fracture. Advances in Physics 55 (3-4): 349-476 MAY-JUN 2006

[23] Hidalgo RC, Kun F, Herrmann HJ. Creep rupture of viscoelastic fibre bundles. Physical Review E 65 (3): Art. No. 032502 Part 1 MAR 2002.

[24] Kun F, Hidalgo RC, Raischel F, Herrmann HJ. Extension of fibre bundle models for creep rupture and interface failure. International Journal of Fracture 140 (14): 255-265 2006.

[25] Nechad H, Helmstetter A, El Guerjouma R, Sornette D. Andrade and critical time-to-failure laws in fibre -matrix composites: Experiments and model. Journal of the Mechanics and Physics of solids 53 (5): 1099-1127 2005a.

[26] Nechad H, Helmstetter A, El Guerjouma R, Sornette D. Creep ruptures in heterogeneous materials. Physical Review Letters 94 (4): Art. No. 0455012005 b

[27] Little RE, Mitchell WJ, Mallick PK. Tensile creep and creep rupture of continuous strand mat polypropylene composites. J Compos Mater 1995;26(16):2215-27. 
[28] Monkman FC, Grant NJ. An empirical relationship between rupture life and minimum creep rate in creep-rupture tests 1956 p. 593-620 [ASTM Special Technical Publication No. 56, Philadelphia].

[29] Wagner, H.D., Schwartz P. \& Phoenix, S.L. 1986. Lifetime Statistics for single Kevlar 49 filaments in creep-rupture. Journal of Material Sciences 21:18681878.

[30] Phoenix, S.L., Schwartz, P. \& Robinson IV, H.H. 1988. Statistics for the strength and lifetime in creep-rupture of model carbon epoxy composites. Composites Science and Technology 32:81-120.

[31] Vujosevic, M., Krajcinovic, D. 1997. Creep Rupture of polymers- a statistical model. Int. J. Solids Structures 34(9):1105-1122.

[32] Hiel, C., Cardon, A. \& Brinson H. 1983b. The nonlinear viscoelastic response of resin matrix composites. Composite Structures 2: 271-281.

[33] Brinson, H.F. 1999. Matrix Dominated Time Dependent Failure Predictions in Polymer Matrix Composites. Composite Structures 47(1-4):445-456.

[34] Schapery, R.A. 1969. On the Characterization of Nonlinear Viscoelastic Materials. Polymer Engineering and Science 9(4):295-310.

[35] Lou, Y.C. \& Schapery, R.A. 1971. Viscoelastic Characterisation of a Nonlinear Fibre -Reinforced Plastic. J. of Composite Materials 5:208-234.

[36] Abdel-Tawab K.; Weitsman Y. J. A Strain-Based Formulation for the Coupled Viscoelastic/Damage Behavior. Journal of Applied Mechanics 68(2) (2001): 304-311.

[37] Hunter, S. C., Tentative Equations for the Propagation of Stress, Strain and Temperature Fields in Viscoelastic Solids, J Mech Phys Solids 1961;9(1):39-51.

[38] Guedes R.M. Mathematical analysis of energies for viscoelastic materials and energy based failure criteria for creep loading. Mechanics of Time-Dependent Materials 2004;8(2):169-192.

[39] Guedes RM. Lifetime predictions of polymer matrix composites under constant or monotonic load. Composites Part A 37 (5): 703-715, 2006.

[40] Schapery R. A. Theory of crack initiation and growth in viscoelastic media. 3. Analysis of continuous growth. Internat. J. Fracture 1975;11(4):549-562.

[41] Christensen R. M. Lifetime predictions for polymers and composites under constant load. J. Rheology 1981;25:517-528. 
[42] Song, M.S., Hua, G.X. and Hub, L.J. Prediction of long-term mechanical behaviour and lifetime of polymeric materials. Polymer Testing 17, 1998, 311332.

[43] Du Z.Z and McMeeking R M. Creep models for metal matrix composites with long brittle fibre s. J. Mechanics Physics Solids 43, 701-726 (1995).

[44] McLean M. Creep deformation of metal-matrix composites. Compos. Sci. Technol. 23, 37-52 (1985).

[45] Curtin WA. Theory of mechanical properties of ceramic-matrix composites. J. Amer. Ceramics Soc. 74, 2837-2845 (1991).

[46] Koyanagi J, Kiyota G, Kamiya T, Kawada H. Prediction of creep rupture in unidirectional composite: Creep rupture model with interfacial debonding and its propagation. Advanced Composite Materials 13 (3-4): 199-213 2004

[47] Yang, Q., Nonlinear viscoelastic-viscoplastic characterization of a polymer matrix composite, Ph.D. Thesis, Free University of Brussels (V.U.B.), 1996.

[48] Moulding Powders Group, 'maranyl, nylon, data for design', Technical Report N110, Moulding Powders Group, ICI Plastics Division, Welwyn Garden City, Herts, 1974.

[49] Challa, S.R. and Progelhof, R.C., A study of creep and creep rupture of polycarbonate, Polymer Engrg. Sci. 35(6), 1995, 546-554.

[50] Corum J. M., Battiste R. L., Brinkman C. R., Ren W., Ruggks M. B., Weitsman Y. J., Yahr G. T., DURABILITY-BASED DESIGN CRITERIA FOR AN AUTOMOTIVE STRUCTURAL COMPOSITE: PART 2. BACKGROUND DATA AND MODELS, OAK RIDGE NATIONAL LABORATORY Report ORNL-6931, February 1998.

[51] Corum J. M., Battiste R. L., Ruggles M. B. and Ren W., Durability-based design criteria for a chopped-glass-fiber automotive structural composite, Composites Science and Technology, Volume 61, Issue 8, June 2001a, Pages 1083-1095

[52] Corum J. M., Battiste R. Deng L., S., Liu K. C., Ruggles M. B. and Weitsman Y. J., OAK RIDGE NATIONAL LABORATORY, Report ORNL/TM2000/322, 2001

[53] Corum J. M., Battiste R. L., Deng S., Ruggles-Wrenn M. B. and Weitsman Y. J., Durability-Based Design Criteria for a Quasi-Isotropic Carbon-Fiber Automotive Composite, OAK RIDGE NATIONAL LABORATORY Report ORNL/TM-2002/39, March 2002

[54] Ren W. Creep behavior of a continuous strand, swirl mat reinforced polymeric composite in simulated automotive environments for durability investigation; 
Part I: experimental development and creep-rupture, Materials Science and Engineering A, Volume 334, Issues 1-2, 1 September 2002a, Pages 312-319.

[55] Ren W. and Robinson DN. Creep behavior of a continuous strand, swirl mat reinforced polymeric composite in simulated automotive environments for durability investigation; Part II: Creep-deformation and model development, Materials Science and Engineering A, Volume 334, Issues 1-2, 1 September 2002b, Pages 320-326

[56] Miyano Y, Nakada M, Nishigaki K. Prediction of long-term fatigue life of quasiisotropic CFRP laminates for aircraft use. International Journal of Fatigue 28 (10): 1217-1225 2006.

[57] Naghdi PM, Murch SA. On the mechanical behavior of viscoelastic/plastic solids. J Appl Mech September 1963;30:321-28.

[58] Crochet MJ. Symmetric deformations of viscoelastic-plastic cylinders. J Appl Mech 1966;33:327-34.

[59] Zhurkov SN. Kinetic concept of the strength of solids. Int J Fract Mech 1965;1(4):311-323.

[60] Knauss, W.G., 'Delayed failure-the griffith problem for linearly viscoelastic materials', Internat. J. Fracture 1970; 6:7-20.

[61] Kostrov, B.V. and Nikitin, L.V., 'Some general problems of mechanics of brittle fracture', Arch. Mech. Stos. (English version) 1970; 22:749-776.

[62] Schapery RA. Theory of crack initiation and growth in viscoelastic media. 1. Theoretical development. Int J Fract 1975a;11(1):141-59.

[63] Schapery RA. Theory of crack initiation and growth in viscoelastic media. 2. Approximate methods of analysis. Int J Fract 1975b;11(3):369-88.

[64] Leon R., Weitsman YJ., 'Time-to-failure of randomly reinforced glass strand/urethane matrix composites: data, statistical analysis and theoretical prediction', Mechanics of Materials 2001;33(3):127-137.

[65] Christensen RM., 'An evaluation of linear cumulative damage (Miner's Law) using kinetic crack growth theory', Mech Time-Dependent Mater 2002;6(4):363-77.

[66] Kachanov, L. M., 'On the Time to Failure Under Creep Conditions', Izv. Akad. Nauk SSR, Otd. Tekhn. Nauk, 1958;8:26-31

[67] Stigh U., 'Continuum Damage Mechanics and the Life-Fraction Rule', Journal of Applied Mechanics, 2006;73(4):702-704. 
[68] Miner MA. Cumulative damage in fatigue. J. Appl. Mech. 12, 1945, A159A164.

[69] Bowman J, Barker MBA. Methodology for describing creep-fatigue interactions in thermoplastic components. Polym Eng Sci 1986;26(22):1582-90.

[70] Yao WX and Himmel N. A new cumulative fatigue damage model for fibrereinforced plastics. Composites Science and Technology 60 (2000) 59-64.

[71] Epaarachchi JA, Clausen PD. An empirical model for fatigue behavior prediction of glass fibre-reinforced plastic composites for various stress ratios and test frequencies, Composites Part A 34(4) (2003): 313-326

[72] Epaarachchi JA. Effects of static-fatigue (tension) on the tension-tension fatigue life of glass fibre reinforced plastic composites. Compos Struct 2006a;74(4):419-25.

[73] Epaarachchi JA. A study on estimation of damage accumulation of glass fibre reinforce plastic (GFRP) composites under a block loading situation. Composite Structures 75 (2006b) 88-89.

[74] Sutherland HJ, Madell JF. The Effect of Mean Stress on Damage Predictions for Spectral Loading of Fibreglass Composite Coupons. Wind Energ.y 2005; 8:93108

[75] Christensen RM. An evaluation of linear cumulative damage (Miner's Law) using kinetic crack growth theory. Mech Time-Depend Mater 2002;6(4):363-77.

[76] Guedes RM. Durability of polymer matrix composites: Viscoelastic effect on static and fatigue loading. Composites Science and Technology 67 (11-12: 25742583, 2007.

[77] Reifsnider KL, Stinchcomb WW. A critical element model of the residual strength and life of fatigue-loaded composite coupons. In: Hahn HT, editor. Composite materials: fatigue and fracture (ASTM STP 907). Philadelphia (PA): American Society for Testing and Materials; 1986. p. 298-313.

[78] Reifsnider K, Case S, Duthoi J. The mechanics of composite strength evolution. Composite Sci Technol 2000;60:2539-46.

[79] Reifsnider K, Case S. Damage tolerance and durability in material systems. Wiley-Interscience; 2002. 